University of Louisville

ThinkIR: The University of Louisville's Institutional Repository

$5-2015$

\title{
Support partners of registered sex offenders : exploring their experiences, identities, and perceptions.
}

David Patrick Connor
University of Louisville

Follow this and additional works at: https://ir.library.louisville.edu/etd

Part of the Criminology and Criminal Justice Commons

\section{Recommended Citation}

Connor, David Patrick, "Support partners of registered sex offenders : exploring their experiences, identities, and perceptions." (2015). Electronic Theses and Dissertations. Paper 2103.

https://doi.org/10.18297/etd/2103

This Doctoral Dissertation is brought to you for free and open access by ThinkIR: The University of Louisville's Institutional Repository. It has been accepted for inclusion in Electronic Theses and Dissertations by an authorized administrator of ThinkIR: The University of Louisville's Institutional Repository. This title appears here courtesy of the author, who has retained all other copyrights. For more information, please contact thinkir@louisville.edu. 


\title{
SUPPORT PARTNERS OF REGISTERED SEX OFFENDERS: EXPLORING THEIR EXPERIENCES, IDENTITIES, AND PERCEPTIONS
}

\author{
By \\ David Patrick Connor \\ B.A., Northern Kentucky University, 2009 \\ M.S., University of Louisville, 2012
}

\begin{abstract}
A Dissertation
Submitted to the Faculty of the

College of Arts and Sciences of the University of Louisville in Partial Fulfillment of the Requirements

for the Degree of
\end{abstract}

Doctor of Philosophy in Justice Administration

Department of Justice Administration
University of Louisville
Louisville, Kentucky

May 2015 


\section{Copyright 2015 by David Patrick Connor}

All rights reserved 

SUPPORT PARTNERS OF REGISTERED SEX OFFENDERS:

EXPLORING THEIR EXPERIENCES, IDENTITIES, AND PERCEPTIONS

\author{
By \\ David Patrick Connor \\ B.A., Northern Kentucky University, 2009 \\ M.S., University of Louisville, 2012
}

A Dissertation Approved on

March 31, 2015

by the following Dissertation Committee:

Dissertation Director

Richard Tewksbury

Cherie Dawson-Edwards

Theresa C. Hayden

Elizabeth Ehrhardt Mustaine 


\section{ACKNOWLEDGEMENTS}

I would like to acknowledge my Dissertation Director and mentor, Dr. Richard Tewksbury, for his assistance and support throughout my graduate school experience. He has afforded me with endless opportunities to overcome obstacles and prosper in the face of adversity. I would also like to thank Dr. Cherie Dawson-Edwards, Dr. Theresa C. Hayden, and Dr. Elizabeth Ehrhardt Mustaine for their willingness to endorse this

project. At the same time, I would like to express my sincere appreciation to Dr. Edward J. Connor, Dr. J. Thomas Muehleman, Ms. Becky Whaley, and Ms. Deborah Dawdy for facilitating the process of data collection. In addition, the informed consent of the men who were undergoing treatment and their support partners made my dissertation possible. Thanks to each of you. Further, my partner, Amanda Denton, deserves recognition for her patience, support, and willingness to share her life with me. I love you. Lastly, I would like to recognize my parents - Mark and Lisa - and siblings - Adam, Dennis, Stephanie, Danielle, and Jon - for their unyielding encouragement and love. 


\begin{abstract}
SUPPORT PARTNERS OF REGISTERED SEX OFFENDERS: EXPLORING THEIR EXPERIENCES, IDENTITIES, AND PERCEPTIONS

David Patrick Connor
\end{abstract}

May 8, 2015

Although it is widely recognized that many convicted criminal offenders experience considerable setbacks in communities that make their lives more arduous, registered sex offenders (RSOs) who live in American society arguably face more challenging impediments. As a result, ensuring their access to social support is especially salient. The notion that social support is particularly relevant to RSOs is perhaps best manifested through a common feature of community-based sex offender treatment programs, where participating RSOs are obligated to forge social relationships with primary support partners. These individuals are an important population to examine, as they purportedly play important roles with respect to helping a particularly stigmatized group of criminal offenders - RSOs - successfully reintegrate into society as productive, law-abiding citizens. And yet, relatively little is known about individuals who have a social link with and provide social support to publicly identified sex offenders, and no previously identified study has specifically examined support partners of RSOs. Thus, in order to provide critical, informative, and rich knowledge about individuals presumably closest to RSOs, the present study utilizes in-depth qualitative interviews with 38 support partners across two sex offender treatment programs in the South. Analyses focus on 
their motivations for serving as support partners, costs associated with such roles, stigma management techniques, and attitudes and beliefs toward sex offender registration and notification (SORN). Contributions to knowledge, limitations, and corresponding policy implications are discussed. 


\section{TABLE OF CONTENTS}

\section{PAGE}

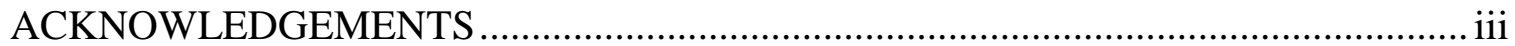

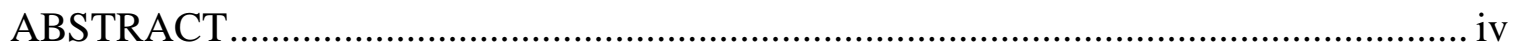

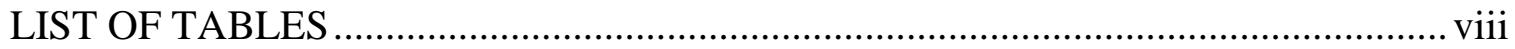

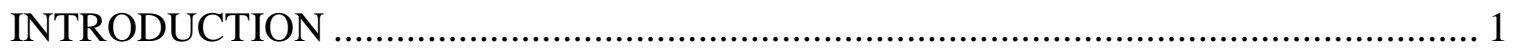

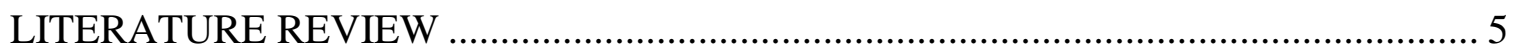

Sex Offender Registration and Notification (SORN) …………......................... 5

Social Support for Ex-offenders ……………………................................. 25

Sex Offender Treatment in the Community....................................................... 29

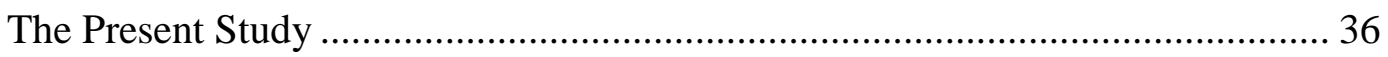

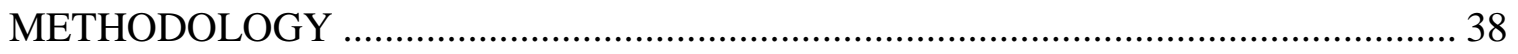

Sample

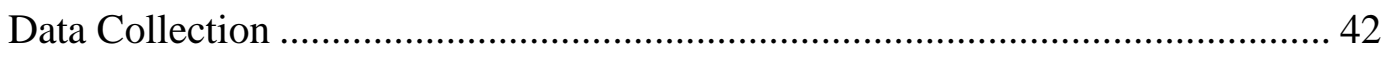

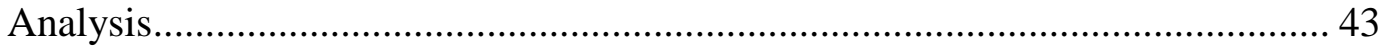

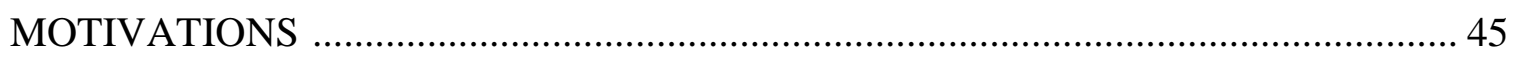




\section{LIST OF TABLES}

$\begin{array}{lll}\text { TABLE } & \text { PAGE }\end{array}$

1. Demographic Characteristics 40

2. Types of Activities Undertaken 


\section{CHAPTER I}

\section{INTRODUCTION}

Although it is widely recognized that many convicted criminal offenders experience considerable setbacks in communities that make their lives more arduous (Tewksbury \& Connor, 2012a; Travis, Solomon, \& Waul, 2001; Visher, La Vigne, \& Travis, 2004), registered sex offenders (RSOs) who live in American society arguably face more challenging impediments (Burchfield \& Mingus, 2008; Levenson \& Cotter, 2005a; Levenson, D’Amora, \& Hern, 2007; Levenson \& Hern, 2007; Mercado, Alvarez, \& Levenson, 2008; Robbers, 2009; Tewksbury, 2004, 2005; Tewksbury \& Lees, 2006a, 2007; Zevitz \& Farkas, 2000a). After being publicly identified as sex offenders, individuals commonly experience feelings of anxiety, depression, embarrassment, isolation, and shame (Burchfield \& Mingus, 2008; Levenson \& Cotter, 2005a; Levenson et al., 2007; Robbers, 2009; Tewksbury, 2012). Harassment and ostracism from community members may also be encountered by known sex offenders (Levenson \& Cotter, 2005a; Tewksbury, 2005; Tewksbury \& Lees, 2006a; Zevitz \& Farkas, 2000a). In addition, the stigma that is associated with labeling as a sex offender, especially in regards to issues of employment, education, and community activity (Tewksbury, 2012; Tewksbury \& Lees, 2006a, 2007; Uggen, Manza, \& Behrens, 2004; Zevitz \& Farkas, 2000a), may become a significant obstacle for such individuals. Further, RSOs often must live in socially disorganized communities or rural locations with limited employment, treatment, and transportation opportunities (Tewksbury \& Mustaine, 2006, 
2008). Thus, because RSOs likely face more hardships than other criminal offenders, ensuring their access to social support may be especially salient.

Social support is important with respect to minimizing subsequent criminal behavior and enabling successful reintegration. Prior research indicates that lower recidivism rates are common among former inmates who have social support throughout their incarceration (Arditti, Lambert-Shute, \& Joest, 2003; Klein, Bartholomew, \& Hibbert, 2002). For instance, prison visits from loved ones significantly decrease the risk of backsliding into criminal activity (Bales \& Mears, 2008; Duwe \& Clark, 2013). Interpersonal attachments also prove to be influential in assisting ex-offenders with community employment (Berg \& Huebner, 2011). Further, social relationships often afford ex-offenders with opportunities for financial assistance and housing (La Vigne, Visher, \& Castro, 2004; Nelson, Deess, \& Allen, 1999; Visher et al., 2004; Visher, Yahner, \& La Vigne, 2010).

The notion that social support is particularly relevant to RSOs is perhaps best manifested through a common feature of sex offender treatment programs, where participating RSOs are obligated to forge social relationships with primary support partners in the community. By guaranteeing that RSOs have at least one prosocial contact in the community, probation and parole officials and treatment providers attempt to add an additional layer of influence and surveillance to the everyday lives of sex offenders who are living in society. Reduction of subsequent criminal behavior and demonstration of a crime-free lifestyle that should be imitated are the desired results of such associations. Support partners of RSOs are an important population to examine, as they purportedly play an important role with respect to helping a particularly stigmatized 
group of criminal offenders successfully reintegrate into society as productive, lawabiding citizens.

And yet, relatively little is known about individuals who have a social link with and provide social support to publicly identified sex offenders. However, available studies suggest that family members of RSOs are likely to experience negative repercussions (Comartin, Kernsmith, \& Miles, 2010; Farkas \& Miller, 2007; Levenson \& Tewksbury, 2009; Tewksbury \& Levenson, 2009). For instance, Farkas and Miller (2007) focused on adult family members of publicly labeled sex offenders, interviewing 72 family members (within 28 families) from six different states. Chronic hopelessness, depression, and frustration that stemmed from adjusting to life with a publicly identified sex offender were the most commonly reported feelings. Interestingly, some family members also expressed that relationships with other relatives deteriorated, as a direct result of their decision to remain in contact with a known sex offender.

Similarly, with online survey data from 584 family members across the United States, Levenson and Tewksbury (2009) and Tewksbury and Levenson (2009) found that individuals related to RSOs commonly experienced adverse consequences. Most family members $(86 \%)$ endured a significant amount of stress, as a result of their association with a RSO, and nearly one-half (49\%) often felt afraid for their own safety because of their loved one's status (Tewksbury \& Levenson, 2009). One-half of the family members lost friends or a close relationship, and 66\% said that shame and embarrassment often prevented them from participating in community activities (Tewksbury \& Levenson, 2009). Individuals who lived with a known sex offender were more likely than individuals who did not live with a known sex offender to encounter threats and 
harassment by neighborhood residents (Levenson \& Tewksbury, 2009). Children of RSOs also reported unfavorable outcomes, with more than one-half stating that they were treated differently by teachers and other children at school. Related to this, Tewksbury and Humkey (2010) found that, when legally permissible, school officials were likely to prohibit parents who were known sex offenders from attending school events. In a much smaller study, Comartin and colleagues (2010) conducted a focus group with four mothers of RSOs. Like the earlier studies concerning family members, the researchers found that being related to RSOs often generated negative ramifications, such as stigmatization, isolation, and changes in personal relationships.

Ultimately, based on the reported experiences of family members, actively pursuing and maintaining a social relationship with a publicly identified sex offender does not appear to be a desirable responsibility. Although a majority of incarcerated sex offenders who anticipate positive family experiences upon release expect personal acceptance, employment opportunities, and housing options from loved ones (Tewksbury \& Connor, 2012b), how and why loved ones assume such responsibilities is unknown. This suggests that in-depth, qualitative interviews with individuals identified by RSOs as their primary support partners would provide informative, rich, and critical knowledge of the motivations and experiences of those closest to publicly labeled sex offenders, which is largely unavailable in the literature. At the same time, by focusing on the concerns and needs of individuals who maintain a close social linkage to known sex offenders, it may be possible to identify programs and services that help them better assist RSOs with successful community reintegration. 


\section{CHAPTER II}

\section{LITERATURE REVIEW}

Perhaps more than any other type of criminal offender, individuals who have participated in illegal sexual activities have been and continue to be viewed as extreme threats to public safety. Society, as a whole, has consistently looked upon such offenders with disgust and disdain (Quinn, Forsyth, \& Mullen-Quinn, 2004). By the same token, sex crimes have reliably evoked the strongest, deep-seated reactions among community members, when compared with other forms of criminal behavior (Jenkins, 1998; Meloy, 2006). For these reasons, distinct criminal justice and mental health strategies have been exclusively reserved throughout history for convicted sex offenders (Leon, 2011; Petrunik, 2003; Terry, 2013). However, over the past several years, societal responses aimed at sexual lawbreakers have increased in severity. In particular, efforts have materialized to enhance the supervision of these criminals and decrease their opportunities to further perpetrate sex crimes, once they are living in the community (Simon, 1998; Tewksbury \& Connor, 2014).

\section{Sex Offender Registration and Notification (SORN)}

\section{Description and Legal Overview}

Spotlighting society's harsh treatment of sex offenders, one of the most recent developments has been the creation of sex offender registries. Although it is not a new concept, criminal registration is experiencing a revival (Logan, 2009). Sex offender registries are utilized in every jurisdiction in the United States, and these repositories of 
information provide online access to a wide array of facts about convicted sex offenders and their sex offenses (Mustaine \& Tewksbury, 2013; Tewksbury \& Higgins, 2005). Upon conviction of sex offenses, individuals are typically required to provide local law enforcement and corrections authorities with name, photograph, address, birth date, Social Security number, fingerprints, offense history, date of convictions, and other information. In addition, sex offenders must verify the accuracy of this information on a routine basis for the duration of their registration, which may range from ten years to life (Tewksbury \& Connor, 2014).

The Jacob Wetterling Act (1994) was the first federal law that mandated registration of sex offenders in state-wide databases. As a result of Wetterling and subsequent legislation, each state now has a mandatory registration law that obligates sex offenders to provide their information to law enforcement officials and have this information provided to the public, most often through publicly available, Internet-based registries. However, it was Megan's Law (1996) in New Jersey that created sex offender registration and notification (SORN) legislation that was ultimately replicated nationwide. Culpable for transforming sex offender registries into publicly available online domains, the federal version of this statute (Public Law 104-145) requires state police agencies to make public information about sex offenders.

Many states that use community notification have a three-tiered system based on the purported dangerousness of sex offenders that determines the degree of notification that will take place (Finn, 1997; Goodman, 1996). When sex offenders are categorized as the lowest risk to public safety, notification is typically reserved for law enforcement officials only. Schools, daycares, and other neighborhood organizations are notified of 
the presence of sex offenders posing a medium risk to public safety. Those sex offenders considered the most dangerous, designated at high risk, will generate the most widespread notification, as the general public is notified. However, some jurisdictions subject all convicted sex offenders to community notification.

Like community notification mandates, restrictions on where one may establish a residence may be an accompanying reality that RSOs must face. Well over one-half of all states and numerous municipalities have sex offender residency restriction laws. Residency restriction laws often feature nebulous language to restrict RSOs from living near locations described as "child congregation" areas (Tewksbury \& Connor, 2014). Such places are typically defined to include schools, parks, playgrounds, daycare centers, bus stops, and recreational facilities. Fluctuating between 500 feet and 2,500 feet, residency restriction laws assert that specific distances must be preserved between a sex offender's residence and various landmarks in the community.

On October 28, 2000, the Campus Sex Crimes Prevention Act (i.e., Public Law 106-386) further amended the original Wetterling Act, requiring RSOs studying and working at colleges and universities to provide notice of their status as sex offenders to these institutions of higher learning. College and university officials are required to inform the campus community where information regarding RSOs may be obtained. In fact, many colleges and universities consequently maintain their own distinctive online sex offender registries (Tewksbury \& Lees, 2006b; Tewksbury, 2013). Exposing convicted sex offenders to further public scrutiny, a nationwide databank of RSOs was created in 2005. The Dru Sjodin National Sex Offender Public Registry, as it was named 
in 2006, was designed by the Department of Justice to provide more efficient access to individual state sex offender registries (Tewksbury \& Connor, 2014.)

Most recently, the Adam Walsh Child Protection and Safety Act was signed into law in 2006 by President George W. Bush (Leon, 2011). As a federal law, it includes the Sex Offender Registration and Notification Act (SORNA), which creates a comprehensive and national system for sex offender registration. Specifically, the legislation puts sex offenders into three tiers of risk. Sex offenders who are tier three are considered to be the most serious and must verify their location with law enforcement every three months for the rest of their lives. Sex offenders defined as tier two must update their whereabouts every six months for 25 years, and sex offenders described as tier one must verify their location annually for 15 years (Terry, 2013). At the same time, the Office of Sex Offender Sentencing, Monitoring, Apprehending, Registering, and Tracking (SMART) was authorized by the Walsh Act to ensure that jurisdictions comply with SORNA (U.S. Department of Justice, 2014). Like the earlier federal statutes concerning the public disclosure of sex offenders, all jurisdictions must adhere to the provisions of the Walsh Act or face reduced federal grant funding.

Under the Walsh Act, all states were obligated to establish SORN statutes in compliance with SORNA guidelines by July 2009. The penalty for not adhering to these requirements is the loss of $10 \%$ of federal funding from the Byrne program law enforcement assistance funds (Zilney \& Zilney, 2009). And yet, no states were compliant with the Walsh Act requirements by July 2009, prompting the SMART Office to extend the deadline for compliance to July 27, 2011 (Terry, 2013). At present, however, only 16 states, three territories, and 36 tribes have successfully implemented SORNA guidelines. 
Specifically, according to the National Conference of State Legislatures (2014),

Alabama, Delaware, Florida, Kansas, Louisiana, Maryland, Michigan, Mississippi, Missouri, Nevada, Ohio, Pennsylvania, South Carolina, South Dakota, Tennessee, and Wyoming are considered to be in compliance with the Walsh Act (NCSL, 2014).

The fact that the majority of jurisdictions in the United States have not implemented the Walsh Act indicates that doing so may be problematic for individual states, territories, and tribes. The primary obstacle to implementing the Walsh Act appears to be financial cost. A national survey of states (Harris \& Lobanov-Rostovsky, 2010) identified a wide variety of costs associated with SORNA execution, including system development, reclassification, expanded enforcement personnel, judicial and correctional expenses, and legal expenses related to prosecution, defense, and litigation. Jurisdictions may cover some of these initial costs through Department of Justice programs authorized by the Walsh Act; however, state fiscal analyses revealed significant operational costs that would be necessary to maintain SORNA requirements (Harris \& Lobanov-Rostovsky, 2010). For instance, Virginia does not seem willing to implement the Walsh Act, as it determined that the first year of compliance with SORNA would cost more than $\$ 12,000,000$. The subsequent cost of maintaining SORNA requirements would be approximately $\$ 8,887,000$ annually (Justice Policy Institute, 2008; Virginia Department of Planning and Budget, 2008).

Public Safety and Recidivism Goals

Beyond the financial burden, efforts to publicly identify and announce the whereabouts of convicted sex offenders through SORN have been empirically denounced at the more fundamental levels of public safety and recidivism. Most arguments 
supporting the public monitoring of sex offenders emphasize the welfare of society, particularly the protection of children. The expressed goals of SORN are to promote public safety and reduce recidivism through the pursuit of deterrence. By informing the public about the identity and whereabouts of convicted sex offenders, SORN laws purportedly increase awareness of potential danger among community members. This knowledge afforded to the public allegedly allows community members to be better prepared to avoid situations in which sex offenders, who are residing, studying, working, and otherwise engaging in daily life among them, may have opportunities to repeat criminal behavior. At the same time, the possibilities for participating in criminal activity again are believed to be restricted, as public identification and exposure of previous sexual misconduct supposedly make sex offenders feel more susceptible to the risks associated with repeating criminal behavior. Further, proponents contend that registration will permit law enforcement officials to quickly and easily ascertain the locations of sex offenders in their communities, facilitating sex crime investigations (Powell, Day, Benson, Vess, \& Graffam, 2014).

\section{Making the Public Aware of Sex Offenders}

Despite the assumption that such laws increase awareness of the presence of sex offenders, a large majority of the public does not actively utilize available information that is disseminated through SORN, potentially limiting its ability to protect community members from sex offenders in their neighborhoods. Anderson and Sample (2008) surveyed 1,821 adult Nebraska residents, and they found that most residents (89\%) were cognizant of the fact that a sex offender registry existed in their jurisdiction, but only about one-third (34\%) had used the sex offender registry. Similarly, from a survey of 
733 Michigan residents, Kernsmith, Comartin, Craun, and Kernsmith (2009) found that only $37 \%$ had used the sex offender registry.

This limited use of publicly available information about sex offenders through SORN may subsequently reduce community members' awareness of sex offenders. In Kernsmith et al.'s (2009) study, nearly all residents (99\%) shared a zip code with a RSO, but only $27 \%$ reported that they believed a sex offender lived in their community. Even among those residents who had accessed the state's sex offender registry, only $51 \%$ reported believing a sex offender lived in their community, and only one of these residents lived in a zip code in which no sex offender was registered.

Through mailed surveys with 631 residents in a single county in the southeastern United States, Craun (2010) focused on whether or not residents living near RSOs were aware of their presence in the community. She found that only $31 \%$ of residents who lived within one-tenth of one mile from a RSO were aware of a sex offender in the area, as compared to only $2 \%$ of residents who lived at least one mile away from all RSOs. Even among those living directly adjacent to a RSO, only about $44 \%$ were aware of their neighbor's status as a RSO.

Likewise, utilizing door-to-door survey data from 95 community members in Illinois, Burchfield (2012) found that only 39\% were aware that a sex offender resided in their neighborhood, in spite of the fact that $60 \%$ considered themselves to be familiar with the state's SORN law. Residents in the sample lived in ten Census block groups evenly divided between two suburban counties where at least one RSO also resided. Thus, while community members are largely aware of SORN, such policies do not appear to raise actual public awareness of the presence of local sex offenders. 
Alternatively, when the public is both aware of sex offenders and SORN, they display increased concern, which can also lead to excessive, and perhaps harmful, precautionary behavior. Through telephone surveys with 250 Alabama residents, Caputo and Brodsky (2004) investigated public reactions to SORN. Residents who interpreted community notification as important reported using a greater number of coping strategies to deal with the close presence of sex offenders and reported being more fearful of general victimization, personal victimization, and sexual victimization. Those who were more afraid of victimization reported using more emotion-focused and problem-focused coping.

\section{Reducing Sex Offender Recidivism}

Regardless of whether or not the public uses information available to them or knows about sex offenders through SORN, the impact of SORN is limited, at best, with respect to reducing future sex crimes by convicted sex offenders. There is substantial evidence that SORN does not prevent convicted sex offenders from continuing to participate in sexual misconduct in the community. Schram and Milloy (1995) conducted a natural experiment in Washington, where the experimental group consisted of 125 sex offenders who were subjected to the state's highest level of community notification, and the control group consisted of 90 sex offenders who were not subjected to community notification. Sex offenders in the control group were sentenced before the Washington SORN law was enacted. It was found that no statistically significant difference existed between the recidivism rates of the two groups. Specifically, over a period of one to four years, $19 \%$ of the sex offenders who were subjected to community notification committed another sex offense, compared to $22 \%$ of sex offenders who were not 
subjected to community notification. Moreover, $63 \%$ of repeat sex offenses perpetrated by sex offenders who were subjected to community notification took place in the same jurisdiction where the community notification occurred, leading Schram and Milloy (1995) to determine that SORN did not strongly impact future sexual misconduct. Supporting this notion, Petrosino and Petrosino (1999) assessed SORN in Massachusetts. Using a retrospective research design, they examined the criminal offense history of 136 sex offenders to estimate the potential influence of SORN. Their findings revealed that only $27 \%$ of the RSOs in the sample had prior sex offenses, which signified the portion of sex offenders that would have been impacted by SORN. At the same time, only about one in three of the prior sex offenses was committed against a stranger. This was problematic, because SORN would not likely protect victims from offenders already known to them. Petrosino and Petrosino (1999) concluded that only six sex offenses from the RSOs in the sample may have been prevented through SORN.

Adkins, Huff, and Stageberg (2000) utilized a quasi-experimental design to analyze the impact of Iowa's sex offender registry on recidivism among 434 convicted sex offenders. No significant difference in specific recidivism between RSOs and unregistered sex offenders was reported. Sex offense recidivism was very low for RSOs (3.0\%) and unregistered sex offenders (3.5\%). Consistent with this finding, Maddan (2008) examined the effect of SORN on recidivism among sex offenders in Arkansas over a five-year period. Specifically, he showed that there was no significant difference in sex offense recidivism between RSOs and unregistered sex offenders. RSOs were only slightly less likely to recommit a sex offense (9.5\%), compared to unregistered sex offenders $(10.9 \%)$. 
With data sources that included 14 states, Agan (2007) compared RSOs with unregistered sex offenders, finding no significant differences in sex offense recidivism between them. Specifically, based on the national panel dataset, there was no decrease in the rate of rape following the establishment of SORN, and no significant benefit was found with respect to the reduction of sex offenses, with sex offender data from the Bureau of Justice Statistics. In addition, awareness of the residential locations of sex offenders was not linked to the commission of sex offenses in Washington, DC.

Conducting an evaluation of New York State's SORN law, Sandler, Freeman, and Socia (2008) used 252 months of arrest data and univariate time-series analyses. They found no support for the effectiveness of SORN in reducing sex offenses by previously convicted rapists, child molesters, or sexual recidivists. Interestingly, over $95 \%$ of all sex offense arrests in the sample were committed by first-time sex offenders. The lack of significant influence of SORN on recidivism remained, even when these rates were considered as a whole.

Tewksbury and Jennings (2010) examined SORN in Iowa, using semi-parametric group-based trajectory models. They examined recidivism rates among sex offenders who were released from prisons for the five-year period before (i.e., 1992-1996) and after (i.e., 1997-2001) implementation of SORN and showed limited support for the ability of SORN to impact continued criminal sexual conduct. It was found that $88 \%$ of sex offenders released prior to SORN and $87 \%$ of sex offenders released after SORN did not sexually recidivate in the first five years. Thus, the most populous groups were sex offenders who did not reoffend in the five years following their release from prisons. It was also found that, with respect to sex offenders who did not recidivate, no differences 
between sex offenders who were released prior to SORN and sex offenders who were released after SORN existed, in terms of their distribution across trajectory groups.

Examining the original Megan’s Law in New Jersey, Zgoba, Witt, Dalessandro, and Veysey (2008) analyzed the rearrest rates of sex offenders who were subjected to SORN with the rearrest rates of sex offenders who were not subjected to SORN. Sex offenders who were not obligated to register were sentenced before the New Jersey SORN law was enacted. The researchers used a six-year follow-up and conducted a time-series analysis. Although multivariate analysis to control for between-group differences was not utilized, it was found that SORN had no impact on time to first rearrest, reduction of sex reoffenses, or reduction of the number of victims involved in sex offenses. Most recently, Tewksbury, Jennings, and Zgoba (2012) examined recidivism rates (using an 8 year follow-up period) among sex offenders who were released from prisons for a five-year period before (i.e., 1990-1994) and after (i.e., 19962000) implementation of SORN. They found that whether or not sex offenders were subjected to SORN failed to predict which sex offenders would sexually recidivate.

Thus, based on these studies, it becomes clear that SORN does not effectively deter convicted sex offenders from sexually reoffending. Research from the mid-1990s to present day across several American jurisdictions indicates that SORN fails to improve public safety. So why do SORN laws persist? Why are SORN policies expanding and becoming more inclusive? The answer may lie with public expectations.

\section{Public Attitudes and Beliefs}

Despite evidence suggesting little or no effect of SORN on public awareness and sex offender recidivism rates, general public approval of such sanctions to control 
convicted sex offenders in the community remains. Comartin, Kernsmith, and Kernsmith (2009) used telephone surveys of 703 Michigan residents, and they found that respondents expressed support for numerous, community-based sex offender policies. Employment restrictions limiting sex offenders from working at schools and daycares (95\%) and other child congregation locations (91\%) showed the greatest support among community members. Respondents also expressed high levels of support for restricting sex offenders from living close to schools and daycares (88\%) and other child congregation locations (83\%). In terms of sex offender community notification, most believed it should be conducted by directly notifying neighbors (85\%) and online registration (83\%), while less than one-half felt it should be conducted in the newspaper (42\%). In terms of sex offender community supervision, most (83\%) believed that sex offenders should wear electronic monitoring devices, and about one-half (48\%) felt that sex offenders should have a nighttime curfew. A significant minority (40\%) felt sex offenders in the community should undergo castration.

Surveying 194 Florida residents, Levenson, Brannon, Fortney, and Baker (2007) also found that most members of the general public support a wide array of policies aimed at sex offenders who live in the community. Overall, they found that residents supported sex offender registration and community notification. Only $3 \%$ believed that no information about sex offenders should be made publicly available. More than threequarters believed all sex offenders should be subjected to community notification. In addition, community notification (83\%) and residency restrictions (58\%) were viewed by residents as effective strategies to reduce sex offenses, and about $73 \%$ indicated that they 
would support such sex offender policies even without scientific evidence of their effectiveness in preventing future sexual victimization.

Such endorsement of punitive sanctions for sex offenders in the community, especially without scientific evidence, is likely the result of intense fear reported by members of the general public. Fear of sex offenders appears to be so pervasive among the public that they are willing to subject all individuals convicted of sex offenses who are in the community to castigating criminal justice policies. In Kernsmith, Craun, and Foster's study (2009), 733 Michigan residents were asked questions about their fear of sex offenders and whether or not they agreed with sex offender registration focused on specific types of sex offenders. Most residents reported that they were afraid of pedophiles (80\%), incest offenders (78\%), and juvenile sex offenders (70\%). A majority reported that they were afraid of date rape offenders (66\%), sex offenders with a sex offense that was ten years old (62\%), and spousal rapists (59\%). A significant minority (45\%) reported that they were fearful of statutory rapists. All types of sex offenders, pedophiles (97\%), incest offenders (96\%), juvenile sex offenders $(86 \%)$, date rape offenders $(84 \%)$, sex offenders with a sex offense more than ten years old $(86 \%)$, spousal rapists $(71 \%)$, and statutory rapists (65\%), were seen by a majority of residents as appropriately subjected to sex offender registration. This is consistent with Schiavone and Jeglic's study (2009), where a majority of the public reported that nearly all sex offenders should be required to submit to registration. After surveying 115 community members from 15 different states, they found that high risk sex offenders (89\%), moderate risk sex offenders $(82 \%)$, and low risk sex offenders were seen as appropriately subject to sex offender registration. 
It is clear that the public largely fears all sex offenders, especially those with child victims, and expresses the most desire for such offenders to become subjected to criminal registration. With this in mind, it is important to note that members of the general public, who already largely support punitive sanctions for sex offenders in the community, may be more likely to endorse these policies if they have children. In fact, those with more children are more likely to see community-based strategies aimed at sex offenders as appropriate restrictions.

Using data from a telephone survey with 1,308 Florida residents, Mancini, Shields, Mears, and Beaver (2010) found that residents with children were significantly more likely than residents without children to endorse sex offender residency restrictions. The odds of residents with children supporting these laws rather than not supporting them were 58\% greater than the odds among residents without children. The researchers also found that even greater support for sex offender residency restrictions existed among residents with three or more children. The odds of residents with three or more children supporting these laws, in comparison to residents without children, increased to $70 \%$. Thus, they concluded that "having multiple children (not just one child) significantly increases support for laws that prohibit where sex offenders can live, and this effect appears to be greater among parents with more children" (p. 1026). Correspondingly, in another study, residents who were parents were more likely to value information received about sex offenders living in their community than residents who were not parents (Caputo \& Brodsky, 2004).

Another explanation for widespread support of criminal justice policies aimed at sex offenders in the community may be the popular misconception that sex offenders 
commonly victimize strangers. To determine whether or not such a misconception was related to sex offender registration, Craun and Theriot (2009) surveyed 565 community members in a single county in the southeastern United States. The experimental group (n $=242$ ) was randomly selected from residences that were located within one-tenth of one mile from the listed address of at least one RSO. The control group $(n=323)$ was selected from addresses that were at least one mile away from all RSOs. The researchers found only about $14 \%$ of the entire sample (both the experimental and control group) reported that they were more concerned about someone they knew sexually assaulting a child than a stranger. Fifty-six percent reported that they were equally concerned about a stranger and someone they knew, and about $30 \%$ reported that they were more concerned about a stranger sexually assaulting a child than someone they knew. In terms of percentages between groups, about $34 \%$ of the experimental group and about $27 \%$ of the control group were more concerned about strangers. Thus, Craun and Theriot (2009) concluded that in communities where RSOs reside, awareness of a local sex offender significantly increases the likelihood that a community is more concerned about a stranger sexually assaulting a child.

Craun, Kernsmith, and Butler (2011) utilized telephone surveys with 728 Michigan residents to determine whether or not members of the general public supported extending criminal registries beyond sex offenders, and if so, with which types of offenders. Generally, findings reveal a split among respondents. Fifty-three percent reported that they supported additional, publicly available registries, nearly $43 \%$ reported that they did not want such registries, and $4 \%$ reported that they were undecided. Several indicators positively predicted community support for any type of additional registry. 
Residents who reported higher average scores on support for the requirement of registration for various types of sex offenders, those who had reported that they had accessed the state's sex offender registry, those who had reported that they were a victim of a sex offender, and those who had reported that they knew of someone who had been a victim of a sex offender were more likely to support the creation of additional criminal registries. Conversely, residents who reported that they were convicted of a criminal offense, in comparison to those who did not report that they were convicted of a criminal offense, were less likely to endorse additional criminal registries. This not only suggests that criminal offenders may have a unique vantage point with respect to criminal sanctions, but they may also have important reasons for failing to endorse such policies that are not immediately apparent to the rest of society. Thus, it may be valuable to examine the perspectives of sex offenders themselves about returning to the community under SORN.

\section{Sex Offender Experiences}

Some research has considered the lived experiences of sex offenders with regard to SORN. Studies soliciting the attitudes and beliefs of sex offenders suggest that such offenders occasionally recognize the potential value in community-based sanctions. However, more often than not, sex offenders do not support the distinct criminal justice policies to which they are subject. A large majority report negative, collateral consequences associated with SORN, which may undermine its potential effectiveness, beyond the financial obstacles of implementation and inability to reduce recidivism.

Sex offenders from numerous qualitative studies have reported significant obstacles resulting from SORN that have prevented them from easily reintegrating into 
society. Zevitz and Farkas (2000a) interviewed 30 RSOs in Wisconsin about their perceived experiences with sex offender registration and community notification. Sex offenders described exclusion from their former residences, being ostracized by community members, threats, and harassment. Many sex offenders also discussed emotional harm to their family members, loss of employment, and added pressure from supervision officials resulting from community notification. In addition, one sex offender reported experiencing vigilante attacks.

To further examine potential negative ramifications associated with sex offender registration, Tewksbury and Lees (2006a) interviewed 22 RSOs from Kentucky. Across their sample, they found that employment difficulties, relationships problems, harassment, social stigmatization, and persistent feelings of vulnerability emerged as pervasive experiences. It is also important to note that the researchers believed these issues were experienced more prevalently by the sex offenders in their study than prior literature had suggested for other types of convicted felons. As a result, they concluded that RSOs may experience a more challenging reintegration process.

Setbacks associated with sex offender registration may include problems with social relationships and increased stress. Robbers (2009) used qualitative interviews and surveys with a sample of 153 sex offenders. She showed that the experience of being socially stigmatized and publicly shamed through sex offender policies has serious negative impacts on a sex offender's community involvement. Specifically, she concluded that the experience of sex offender registration reduced social support, created the loss of family relationships and identity as an active citizen, and increased psychological stress. 
More recently, to gauge the degree to which stigmatization is experienced, Tewksbury (2012) utilized semi-structured interviews with 24 incarcerated sex offenders approaching their release dates. His analysis focused on how sex offenders recognized social stigmatization and potential responses to such public labeling. Sex offenders largely reported shame, hopelessness, depression, and fear resulting from perceptions of stigmatization received from both prison and society. In addition, sex offenders commonly expressed resentment towards those they perceived as labeling them. These descriptions by sex offenders are important to consider because public labeling is a significant component to SORN laws.

Research has pointed to numerous collateral consequences directly associated with criminal convictions. These collateral consequences are the unfavorable experiences that may exist in association with criminal penalties (Buckler \& Travis, 2003; Wheelock, 2005). Most studies have approached collateral consequences from the perspective of general felony convictions. Social consequences are largely apparent in the additional, supposedly unintended, outcomes resulting from felony convictions. These issues include stigmatization, employment difficulties, relationship problems, and negative feelings regarding self-image (Dodge \& Pogrebin, 2001; Pogrebin, Dodge, \& Katsampes, 2001).

Extensively interviewing male parolees, Harding (2003) examined the way in which former inmates managed their felonious identity. The ex-convicts revealed that social consequences, particularly stigmatization of convicted felons, make societal reintegration extremely difficult. Academic works concerning felony convictions have also pinpointed numerous legal repercussions, which include employment restrictions, 
loss of voting rights, and other civil limitations (Burton, Cullen, \& Travis, 1987;

Olivares, Burton, \& Cullen, 1996).

Recent studies indicate that the nature and degree of collateral consequences for sex offenders may be greater than for other convicted felons. Drawing on data from 121 RSOs, Tewksbury (2005) found that loss of relationships, employment, and housing, as well as social stigmatization, was experienced by a significant minority of RSOs. The most prominent finding was that more than one-half (54\%) believed that they lost a friend as a result of registration and public knowledge of their sexual offending. In addition, $47 \%$ were harassed in person, $45 \%$ lost or were denied a place to live, and $42 \%$ lost a job.

Likewise, Levenson and Cotter (2005a) surveyed 183 sex offenders in Florida to examine the experiences and consequences of sex offender registration and community notification. Their results are similar to Tewksbury's (2005) findings, as they report that as a result of their status as RSOs, $35 \%$ of the sample was required to relocate to a new residence, $27 \%$ lost their job, and $19 \%$ experienced harassment in some form. These same researchers (Levenson \& Cotter, 2005b) explored the impact of sex offender residency restrictions, which often accompany SORN legislation, by surveying 135 sex offenders in Florida. Fifty-seven percent found it difficult to locate affordable housing, $44 \%$ were unable to live with family members, and approximately $25 \%$ reported that they had to relocate their residence as a result of the state's residency restriction law. Sixty percent of the sex offenders in the study also expressed emotional distress as a direct outcome of the residency restrictions to which they were subjected.

Brannon, Levenson, Fortney, and Baker (2008) showed that, when comparing perceptions and experiences of sex offenders and community residents, sex offenders 
report far more negative experiences arising from SORN than is realized by the public. Almost one-half of sex offenders reported experiencing threats, property damage, and physical assault, while only $10 \%$ of residents were aware of such vigilantism resulting from public disclosure. Correspondingly, in Schiavone and Jeglic's study (2009), only $17 \%$ of the public believed that sex offender registration made sex offenders' reintegration more stressful.

Additionally, Tewksbury and Lees (2006b) examined the experiences of an important subset of RSOs - those listed on university-maintained sex offender registries. Through surveys of such registrants, they found high levels of collateral consequences. Specifically, they reported that $65 \%$ of these sex offenders were not hired or lost a job, $42 \%$ lost or were denied a place to live, and $42 \%$ lost a friend as a result of their registration status. In a qualitative investigation of this population, Tewksbury (2013) discovered that RSOs on university campuses commonly experienced social isolation, as well as intense and unrelenting feelings of vulnerability. The fact that these sex offenders could be found on a university registry, in addition to a state registry, seemed to heighten these undesirable ramifications.

Such adverse consequences are again seen in Tewksbury's (2004) study, where he examined the experiences and perceptions of 40 female sex offenders in Indiana and Kentucky. From the experiences of these women, the researcher found that "far-reaching implications" existed for individuals listed on registries (p. 32). Specifically, a number of negative experiences resulted from sex offender registration. Forty-two percent lost a job, 39\% lost a friend, and 34\% were harassed in person as a result of registration and 
public knowledge of their sex offenses. At the same time, $34 \%$ lost or were denied a place to live.

When these studies are taken together, the contention that a significant number of sex offenders, who are almost invariably exposed to SORN and accompanying residency restrictions in the community, will experience associated negative, unintended consequences that make societal reintegration more challenging is difficult to contest. Because such significant obstacles to moving on with one's life are present in the community for many RSOs, especially when compared with other criminal offenders who are not as intensely subjected to punitive community sanctions, ensuring their access to social support may be especially salient.

\section{Social Support for Ex-offenders}

For all ex-offenders, social support may be important with respect to minimizing subsequent criminal behavior and enabling successful reintegration. There is evidence that prison visits significantly decrease the risk of backsliding into criminal activity in the community. In Florida, Bales and Mears (2008) examined the effects of prison visitation on recidivism among 7,000 inmates. Their results revealed that any number of visits and more frequent visits during the final year of incarceration decreased recidivism risk.

Specifically, among inmates who received visits, the odds of recidivism were almost $31 \%$ lower than the odds for inmates who did not receive visits. At the same time, for each additional visit received by an inmate, the odds of recidivism decreased by nearly $4 \%$.

Similarly, after studying the effects of prison visitation on recidivism among 16,420 inmates released from Minnesota prisons between 2003 and 2007, Duwe and Clark (2013) found that visitation significantly decreased recidivism risk. In particular, 
reconviction for a felony offense was $13 \%$ lower for inmates who received visits, compared to inmates who did not receive visits. The number of distinct visitors was important, too, as each additional visitor received by an inmate was responsible for reducing the risk of a felony reconviction by $3 \%$. Further, visits from family members were more influential than visits from friends. The risk of a felony reconviction was decreased by $21 \%$ for at least one in-law visit, $10 \%$ for a sibling visit, and $9 \%$ for a visit by other relatives. However, any visit from a friend only reduced such risk by $7 \%$.

The Role of Family Associations

This suggests that family members, in particular, may be a valuable source of social support for ex-offenders. Supporting this notion, Visher and Courtney (2006) surveyed 358 men who returned to Cleveland, Ohio, following a period of incarceration. After living in the community for a minimum of one month to a maximum of three months, the largest percentage (26\%) of ex-offenders identified support from family members as the most important influence on maintaining a crime-free lifestyle. At the same time, $78 \%$ of these former inmates received financial support from their families, while $80 \%$ lived with a family member.

Other studies also indicate that family members are able to help ex-offenders with community reintegration through the provision of resources. Using survey data from 247 family members of male ex-offenders, Naser and Visher (2006) examined the ways in which loved ones offered support to newly released felons in Chicago, Illinois. Housing was provided by $76 \%$ of the family members, and help with finding living arrangements (separate from the family member) was provided by $40 \%$ of the family members. Financial assistance was the most common form of support, however, 
provided by $83 \%$ of the family members. Likewise, Visher, Kachnowski, La Vigne, and Travis (2004) found that financial assistance was a common type of support offered by family members, as it was reported by 165 (or just over one-half) of the 324 ex-offenders who returned to Baltimore, Maryland from correctional institutions. Eighty percent of these former inmates were also living with family members during the first three months of their release into the free world.

Nelson and colleagues (1999) conducted qualitative interviews with 49 exoffenders who exited a New York State prison or New York City jail, in an effort to report their experiences in the first month after release. For most ex-offenders, family relationships served an important social support function during this time period. Families provided housing, food, and spending money, as well as emotional support in the form of acceptance and encouragement. Such emotional support from family associations was also reported by numerous ex-offenders in Laub and Sampson's (2003) research, as a factor that led to successful desistance from criminal activity. With longitudinal data from 500 male former delinquents, they concluded that, among those who had not returned to crime, family members were often the first individuals to demonstrate affection and care.

\section{Family Members of RSOs}

Although family associations appear to be a promising means for support that may reduce future criminal behavior and help with the receipt of tangible and intangible resources to get acclimated to society, relatively little is known about individuals who have a social link with and provide social support to a RSO. However, available studies suggest that family members of known sex offenders are likely to experience negative 
repercussions. Farkas and Miller (2007) focused on adult family members of publicly labeled sex offenders, interviewing 72 family members (within 28 families) from six different states. Chronic hopelessness, depression, and frustration that stemmed from adjusting to life with a publicly identified sex offender were the most commonly reported feelings. Interestingly, some family members also expressed that relationships with other relatives deteriorated, as a direct result of their decision to remain in contact with a RSO.

Similarly, with online survey data from 584 family members across the United States, Levenson and Tewksbury (2009) and Tewksbury and Levenson (2009) found that individuals related to a publicly identified sex offender commonly experienced adverse consequences. Most family members $(86 \%)$ endured a significant amount of stress, as a result of their association with a RSO, and nearly one-half (49\%) often felt afraid for their own safety because of their loved one's status as a sex offender (Tewksbury \& Levenson, 2009). One-half of the family members lost friends or a close relationship, and $66 \%$ said that shame and embarrassment often prevented them from participating in community activities (Tewksbury \& Levenson, 2009). Individuals who lived with a RSO were more likely than individuals who did not live with a known sex offender to encounter threats and harassment by neighborhood residents (Levenson \& Tewksbury, 2009). Children of sex offenders also reported unfavorable outcomes, with more than one-half stating that they were treated differently by teachers and other children at school. Related to this, Tewksbury and Humkey (2010) found that, when legally permissible, school officials were likely to prohibit parents who were RSOs from attending school events. In a much smaller study, Comartin and colleagues (2010) conducted a focus group with four mothers of RSOs. Like the earlier studies concerning family members, the researchers 
found that being related to a publicly labeled sex offender often generated negative ramifications, such as stigmatization, isolation, and changes in personal relationships.

Ultimately, based on the reported experiences of family members, actively pursuing and maintaining a social relationship with a publicly identified sex offender does not appear to be a desirable responsibility. Although a majority of incarcerated sex offenders who anticipate positive family experiences upon release expect personal acceptance, employment opportunities, and housing options from loved ones (Tewksbury \& Connor, 2012b), how and why loved ones assume such responsibilities is unknown. This suggests that in-depth, qualitative interviews with individuals identified by RSOs as their primary support partners would provide informative, rich, and critical knowledge of the motivations and experiences of those closest to publicly labeled sex offenders. The utilization of support partners is an important component of many community-based sex offender treatment programs.

\section{Sex Offender Treatment in the Community}

Following a criminal conviction for a sex offense, not only is an individual generally obligated to register as a sex offender, which may be accompanied by notification mandates and residency restrictions, but he or she may also be required to participate in and successfully complete a sex offender treatment program. Convicted sex offenders may volunteer or be compelled to engage in sex offender treatment while incarcerated; however, lawbreakers who are adjudicated as sex offenders commonly experience such treatment in the community. This is because many sex offenders do not spend a significant amount of time behind bars, as their criminal cases are often resolved through community-based sanctions, rather than extended periods of time locked inside 
correctional institutions (Abadinsky, 2012; Greenfeld, 1997; Stalans, 2004; Terry, 2013). Even when sex offenders are confined inside prisons, most of them are eventually released from incarceration (Petersilia, 2003; Tewksbury \& Connor, 2012a) and frequently rejoin society as parolees. Between 10,000 and 20,000 sex offenders are annually released from American correctional institutions (Center for Sex Offender Management, 2007; Harrison \& Beck, 2006; Hughes \& Wilson, 2003), and today, more than 700,000 individuals in the United States are RSOs (National Center for Missing and Exploited Children, 2014). Satisfactory involvement in and eventual completion of a sex offender treatment program in the community are almost always expectations that a convicted sex offender on conditional release must meet, as well as prerequisites for receiving an ultimate discharge from supervision. In any event, it is important to understand why convicted perpetrators of sex offenses are often made to partake in sex offender treatment.

\section{Treatment as a Public Safety Tool}

Increased public knowledge of sex offenders and their presence in the community, as well as the growth of responses to sex offenses, may be responsible for the development of treatment programs specifically designed for individuals convicted of sex offenses (Connor, Copes, \& Tewksbury, 2012). Like sex offender registration, notification, and residency restrictions, the primary purpose of sex offender treatment is to increase public safety by preventing recidivism (Gerardin \& Thibaut, 2004; Patel, Lambie, \& Glover, 2008; Zgoba \& Simon, 2005). Specifically, desistance from future sex crimes by previously convicted sex offenders is the desired end (Williams, 2009). Unlike sex offender registration, notification, and residency restriction policies, however, 
sex offender treatment programs appear to be a promising means for managing sex offenders in the community.

Hall (1995) was perhaps the first to use meta-analysis to discern the influence of sex offender treatment on convicted sex offenders' subsequent behavior. Using 12 studies that compared sex offenders who participated in sex offender treatment with sex offenders who did not participate in sex offender treatment, he found that completion of such a treatment curriculum minimized the commission of additional sex offenses. Specifically, among 1,313 sex offenders, treated sex offenders sexually reoffended at a rate of $19 \%$, whereas untreated sex offenders sexually reoffended at a rate of more than 27\%. Correspondingly, the General Accounting Office (1996) of the United States examined 22 reviews of sex offender treatment, concluding that such "treatment programs showed promise for reducing deviant sexual behavior” (p. 11).

Several years later, Hanson and colleagues (2002) conducted a meta-analysis that covered 43 sex offender treatment studies. Overall, among 9,454 sex offenders, they discovered that those who completed a sex offender treatment program recidivated less than those who did not complete a sex offender treatment program. In terms of sexual recidivism, treated sex offenders committed another sex offense at a rate of only $12 \%$, whereas untreated sex offenders committed another sex offense at a rate of nearly $17 \%$. With respect to any type of additional criminal behavior, the general recidivism rate for treated sex offenders was $32 \%$, while the general recidivism rate for untreated sex offenders was much higher, at a rate of $51 \%$.

A subsequent meta-analysis by Losel and Schmucker (2005) revealed similar results about the efficacy of sex offender treatment curriculums. Following an 
examination of 22,181 sex offenders across 69 studies, they found that those who completed a sex offender treatment program sexually recidivated at a rate of only $11 \%$, compared to untreated sex offenders, who committed another sex offense at a rate of nearly $18 \%$. In terms of future violence, treated sex offenders committed another criminal offense that was considered violent at a rate of only $6 \%$, whereas untreated sex offenders committed another criminal offense that was considered violent at a rate of nearly $12 \%$. Regarding any type of additional criminal behavior, the general recidivism rate for treated sex offenders was $22 \%$, while the general recidivism rate for untreated sex offenders was almost $33 \%$.

Based on these investigations, the differences in recidivism rates between sex offenders who receive treatment and sex offenders who do not receive treatment may seem modest. However, it is important to note that sex offenders, on the whole, have relatively low rates of recidivism (Furby, Weinrott, \& Blackshaw, 1989; Sample \& Bray, 2006), especially in comparison to other criminal offenders (Langan \& Levin, 2002;

Sample \& Bray, 2003). It is also necessary to recognize that seemingly small influences on whether or not convicted sex offenders return to criminal behavior may, nonetheless, be meaningful. Reflecting on this notion, Prentky and Schwartz (2006) posited that, out of every 100,000 convicted sex offenders, if treatment curriculums decreased sexual recidivism only by $5 \%$, the outcome may still be 5,000 fewer repeat sex offenders. They contended that "relatively small reductions in sexual recidivism rates can have a notable impact on the number of victims" (p. 5).

Thus, given the growing evidence of its effectiveness with minimizing subsequent criminal behavior, especially sex offenses, treatment specifically designed for sex 
offenders may be a valuable mechanism for meeting the safety needs of the public. At the same time, sex offender treatment programs may serve as a critical form of social support, helping sex offenders successfully reintegrate into the community. The utilization of support partners throughout the treatment process is one attempt to ensure such support.

\section{Support Partners as Mentors}

A common feature of sex offender treatment programs obligates a participating RSO to forge a social relationship with a primary support partner in the community. By guaranteeing that RSOs have at least one prosocial contact in the community, probation and parole officials and treatment providers attempt to add an additional layer of influence and surveillance to the everyday lives of sex offenders who are living in society. Reduction of subsequent criminal behavior and demonstration of a crime-free lifestyle that should be imitated are the desired results of such associations. Support partners may be thought of as mentors who have the responsibility to help RSOs fully participate in the treatment process and prosocially navigate their lives in the community through the delivery of social support.

Although no previously identified study has specifically examined the lived experiences of support partners of RSOs undergoing treatment, the relevant literature describes some recent programs with a mentoring component that facilitate successful community reintegration. Interestingly, in Duwe and Clark's (2013) study of social support, receiving a prison visit from a mentor was responsible for the greatest reduction in felony reconviction risk among released inmates, at nearly $30 \%$. When social support 
is transferred to ex-offenders in the community, the positive influence of mentoring on future behavior often remains.

\section{Community Mentoring Programs for Ex-Offenders}

The Circles of Support and Accountability (COSA), a Canadian mentoring program for formerly incarcerated sex offenders, pairs these offenders with a relapse prevention team that consists of four to six community volunteers (Hannem \& Petrunik, 2007). The volunteers, acting as mentors, meet regularly with released sex offenders at churches, restaurants, and other locations in the community to promote societal inclusion. They also provide social support by helping sex offenders to secure jobs and housing, identify community resources, appropriately deal with disappointments, and celebrate achievements. With a sample of COSA participants and 60 non-COSA participants, who were matched based on estimated risk to reoffend, length of time in the community, and prior involvement in sex offender treatment, an evaluation of COSA showed promising results. Over a three-year period, COSA participants were significantly less likely to sexually recidivate (i.e., $5 \%$ compared to almost $17 \%$ ), violently recidivate (i.e., $15 \%$ compared to $35 \%$ ), and generally recidivate (i.e., $28 \%$ compared to $43 \%$ ) than non-COSA participants (Wilson, Picheca, \& Prinzo, 2005).

Aimed at improving the post-release success of drug offenders rather than sex offenders, La Bodega is a program designed for family members to help them better support these offenders in the community (Sullivan, Mino, Nelson, \& Pope, 2002). Counseling sessions are conducted with ex-offenders and their family mentors, in order to help family members adjust to life with ex-offenders with a history of illegal substance use, while also instructing them how to best serve the needs of such offenders. The idea 
is that these efforts will make drug treatment more effective. With a sample of $50 \mathrm{La}$ Bodega ex-offenders and 56 non-La Bodega ex-offenders, an evaluation revealed promising results. At a six-month follow-up, a statistically significant difference was found, as La Bodega ex-offender participants reported a 38\% reduction in illegal substance use, compared to a $13 \%$ reduction in illegal substance use reported by non-La Bodega ex-offenders. Qualitative findings showed that family members who participated in La Bodega learned how to become effective mentors, by altering their own supportive behaviors, in order to facilitate abstinence from illegal substance use and avoid enabling such activity.

Qualitative analyses also revealed that support partners of adult male ex-offenders who participated in Project Greenlight benefited from participation in the program (Wilson, 2007; Wilson \& Davis, 2006). Specifically, program staff described many episodes where support partners' ability to recognize the needs of ex-offenders, encourage ex-offenders regarding expectations, and collectively work with ex-offenders to develop a plan for their successful reintegration were improved as a result of the engaging in the program.

Plans for successful reentry often involve obtaining employment. Ready4Work aimed to increase the employment rates of ex-offenders, while strengthening their social support through the use of mentors (Bauldry, Korom-Djakovic, McClanahan, McMaken, \& Kotloff, 2009). This program was tested in 11 different locations throughout the United States, including Chicago, Detroit, Houston, Jacksonville, Los Angeles, Memphis, Milwaukee, New York, Oakland, Philadelphia, and Washington, DC. One year after release, ex-offenders who were mentored while participating in Ready4Work were 35\% 
less likely to reoffend, compared to ex-offenders who were not mentored during the program. If ex-offenders were rearrested, reconvicted, or incarcerated again, they were considered to have recidivated. Among ex-offenders who were mentored, longer periods of time with a mentor indicated greater odds of obtaining employment. Each additional month of mentoring was associated with a slight reduction in an ex-offender's risk of recidivism. Qualitative findings revealed that mentored ex-offenders felt supported by mentors, as mentors helped them to remain motivated, reduce stress, and learn about basic life skills.

\section{The Present Study}

Although the perspectives of mentored ex-offenders were revealed in the study by Bauldry and colleagues (2009), the feelings, activities, motivations, and overall experiences of individuals who mentor a particularly stigmatized and heavily sanctioned group of criminal offenders - support partners of RSOs - are largely unknown. They are an important population to examine, as they purportedly play an important role with respect to helping such criminal offenders successfully reintegrate into society as productive, law-abiding citizens. The significance of examining the lived experiences of these mentors in the context of treatment, public safety, and successful reintegration is heightened, when considering the failure and unintended consequences of other criminal justice approaches aimed at sex offenders, such as SORN and residency restrictions. This is the purpose of the present research.

Beyond examining a previously untapped population, by focusing on individuals who maintain a close social linkage to RSOs, the present study may help to identify programs and services that support partners need to better assist such ex-offenders with 
successful community reintegration. Specifically, once it is understood why support partners choose to assist RSOs with completion of treatment and reintegration (see Chapter IV), incentives and other rewards may be identified and subsequently implemented to increase social support for these ex-offenders. At the same time, by exploring costs associated with accepting and maintaining close relationships with RSOs (see Chapter V), the development of feasible remedies to counteract such negative consequences and ensure adequate social support may be possible. Further, successful strategies to manage likely stigmas (see Chapter VI), once identified and subsequently adopted, may help future individuals close to stigmatized persons minimize unpleasant ramifications and offer stronger support. What is more, as a group of individuals who are intimately associated with RSOs, support partners presumably have unique experiences with and impressions about SORN (see Chapter VII) that may assist with further understanding the utility of such legislation. 


\section{CHAPTER III}

\section{METHODOLOGY}

Data for the present study originated from semi-structured qualitative interviews conducted with 38 support partners of RSOs across two sex offender treatment programs in the South. Although the number of support partners who participated in this research was relatively small, the present investigation represented an exploratory endeavor aimed at a previously unexamined population. Thus, the goal of the project was to interview enough participants to reach saturation (i.e., when no new themes or information arose from additional interviews). After completing the interviews and examining the available data, the researcher was confident that thematic saturation was indeed achieved, especially given the fact that saturation may be reached with as few as 12 interviews (Guest, Bunce, \& Johnson, 2006). At the same time, although there are no clear, universally accepted guidelines for how many interviews are sufficient to reach thematic saturation, a review of ethnographic research in the leading criminology and criminal justice journals indicated that the median sample size was 35 for studies based on semistructured interviews (Copes, Brown, \& Tewksbury, 2011). Thus, with a total sample size of 38 , the number of interviews included in the analyses was believed to be satisfactory. Further, no previously identified study focused on the primary support partners of RSOs who were undergoing treatment, making this in-depth data source an appropriate starting point for knowledge attainment and future inquiry.

\section{Sample}


Table 1 shows the demographic characteristics of the sample. Support partners were mostly female (76.3\%), almost entirely White (94.8\%), and largely married (71.1\%). Overall, participants ranged in age from 24 to 85 , with a mean age of 54.4 years. Interestingly, a majority of support partners (52.6\%) possessed a postsecondary degree. Of these participants, just less than one-fifth (18.4\%) held a two-year college degree, nearly one-quarter (23.7\%) held a four-year college degree, and one-tenth $(10.5 \%)$ held a graduate degree. About one-fifth $(21.1 \%)$ had some college experience, and another one-fifth (21.0\%) completed high school. A small proportion of support partners (5.3\%) did not complete high school.

All support partners in the present study forged formal relationships with RSOs who were adult males undergoing sex offender treatment. This should not be surprising, however, as RSOs are typically men. Earlier research reported that between $0.8 \%$ and 3.0\% of RSOs were women (Adkins et al., 2000; Terry, 2013; Tewksbury, 2004; Vandiver \& Walker, 2002). At the same time, all participants were family members of the RSOs who they supported. Specifically, more than one-third (36.8\%) were parents, more than one-fourth were spouses (28.9\%), and more than one-tenth $(13.2 \%)$ were siblings. A small proportion of support partners were ex-spouses (7.9\%) and grandparents (5.3\%). One brother-in-law, one child, and one uncle were also in the sample, representing about eight percent of participants, collectively. Although prior studies examined family members of RSOs (Comartin et al., 2010; Farkas \& Miller, 2007; Levenson \& Tewksbury, 2009; Tewksbury \& Levenson, 2009), individuals in the present study represented a distinct and untapped population. They were specifically selected by RSOs to serve formal supporting roles in the sex offender treatment process 
and thus are presumably closer to such offenders than other relatives. In this way, these support partners, albeit family members, are likely equipped with unique experiences and insights.

\section{Table 1}

\section{Demographic Characteristics of Support Partners}

\begin{tabular}{lc}
\hline Variable & Value \\
\hline
\end{tabular}

$\operatorname{Sex}$

Female

$76.3 \%(\mathrm{n}=29)$

Male

$23.7 \%(\mathrm{n}=9)$

Race

White

$94.8 \%(\mathrm{n}=36)$

Black

$2.6 \%(\mathrm{n}=1)$

Asian

$$
2.6 \%(\mathrm{n}=1)
$$

Marital status

Married

Divorced

Single

Widowed

Age (mean)

Education

Less than high school

High school

Some college
$71.1 \%(\mathrm{n}=27)$

$13.1 \%(\mathrm{n}=5)$

$10.5 \%(\mathrm{n}=4)$

$5.3 \%(\mathrm{n}=2)$

54.4 (range $24-85)$

$$
5.3 \%(\mathrm{n}=2)
$$

$21.0 \%(\mathrm{n}=8)$

$21.1 \%(\mathrm{n}=8)$ 
Two-year college degree

Four-year college degree

Graduate degree

Relationship

Parent

Spouse

Ex-Spouse

Sibling

Other (i.e., brother-in-law, child, and uncle)
$18.4 \%(\mathrm{n}=7)$

$23.7 \%(\mathrm{n}=9)$

$10.5 \%(\mathrm{n}=4)$

$36.8 \%(\mathrm{n}=14)$

$28.9 \%(\mathrm{n}=11)$

$7.9 \%(\mathrm{n}=3)$

$13.2 \%(\mathrm{n}=5)$

$7.9 \%(\mathrm{n}=3)$

Table 2 presents the types of activities that were undertaken by participants while supporting RSOs. All support partners reported offering emotional support and participating in sex offender treatment sessions. Most participants $(84.2 \%)$ provided housing accommodations to RSOs, and a significant minority (42.1\%) allowed RSOs to live with them. A majority socialized with RSOs outside of treatment (78.9\%) and helped them financially (65.8\%). Over one-half (57.9\%) assisted RSOs with searching for employment.

\section{Table 2}

Types of Activities Undertaken by Support Partners

\begin{tabular}{lr}
\hline Variable & Value \\
\hline Offer emotional support & $100 \%(\mathrm{n}=38)$ \\
Participate in sex offender treatment & $100 \%(\mathrm{n}=38)$ \\
Provide housing accommodations & $84.2 \%(\mathrm{n}=32)$
\end{tabular}




\section{Data Collection}

The researcher partnered with two forensic psychologists, who each operated a sex offender treatment program at their respective practices, in order to enlist participation in the present study. By collaborating with these treatment providers, the researcher was able to gain access to individuals who served as support partners of RSOs. The treatment providers, who devoted most of their time to working with convicted sex offenders and their loved ones, actively vouched for the researcher throughout the data collection process, confirming for these populations that he was of nonjudgmental character, not affiliated with the criminal justice system, and interested in understanding their experiences. They also provided support partners, who were identified by RSOs in their sex offender treatment programs, with recruitment flyers, following periodic therapy sessions that included both parties (i.e., RSO and his support partner). The recruitment flyer explained the research project and invited support partners to contact the researcher to schedule one-on-one, personal interviews if they wished to participate in the study. Support partners who expressed immediate interest had the option to directly sign up for interviews with the respective executive assistant for each practice. 
Interviews with a nonrandom, purposive sample of individuals, who were identified by RSOs as their primary support partners, were conducted over a nine-month period from March 2014 to November 2014. The interviews were semi-structured to avoid imposing artificial concepts and categories on support partners, which allowed participants to speak freely using their own terminology. This style of interviewing permitted support partners to discuss their thoughts and beliefs in detail. Moreover, it allowed the researcher to gain extensive knowledge about their motivations for serving as a support partner, costs of serving as a support partner, stigma management strategies, and attitudes and beliefs about SORN. Thirty-three interviews were conducted face-toface; 27 of these interviews were carried out inside a private office on the grounds of the first treatment provider's practice, and six of these interviews took place inside a private office on the grounds of the second treatment provider's practice. The additional five interviews were completed via telephone. The duration of interviews varied from support partner to support partner; however, on average, they transpired over a period of 90 minutes. Prior to data collection, all procedures were reviewed by the researcher's university institutional review board, in order to ensure that ethical standards were met.

\section{Analysis}

All interviews were transcribed in full. The researcher made every attempt to transcribe the interviews in a way that reflected natural speaking patterns; however, some words and phrases were edited to aid readability. All identifying information was removed during this process, and each support partner and referenced RSO was assigned an alias to protect his or her confidentiality. 
Data were manually coded, following principles of analytic induction in multiple readings (Charmaz, 1983, 2006). This approach utilized numerous readings of all transcripts, with each reading focused on a narrow range of issues and conceptual categories. As this was an exploratory investigation, open coding was used, and findings reflected issues that emerged from the data during the coding for the concepts of primary interest (i.e., motivations, costs, stigma management, and SORN). 


\section{CHAPTER IV}

\section{MOTIVATIONS FOR SERVING AS A SUPPORT PARTNER}

A description of support partners who participated in the present study was

provided in Chapter III. This included a breakdown of their demographics and activities that were undertaken while supporting RSOs. Although it was clear from descriptive statistics that support partners all had preexisting familial relationships with RSOs and commonly offered emotional support and housing accommodations to them, such information provided only a cursory look at participants. Hence, what follows here, as well as in Chapters V, VI, and VII, is a more in-depth examination of support partners and their experiences. Specifically, in this chapter, the varying rationales behind support afforded to RSOs are described, using data from qualitative interviews with participants. Once it is understood why support partners chose to assist RSOs with completion of treatment and reintegration, incentives and other rewards may be identified and subsequently implemented to increase social support for these ex-offenders.

Analysis of interview data revealed that there were two primary sets of motivations that prompted participants to serve as support partners of RSOs. One group of themes concerned the initial reasons why participants agreed to forge formal associations with RSOs, whereas the other group involved explanations for continuation or maintenance of the support-partner-sex-offender relationship. In terms of initial motivations, support partners formed these formal associations, because they believed 
that no one else would serve in such roles, they could minimize the negative impacts of returning to society, and RSOs had redeemable qualities. With respect to reasons for preserving formal relationships, participants believed that such associations allowed them to become closer to RSOs and gave their lives a sense of purpose. Although these motivations were widespread, the perspectives of support partners regarding such driving forces reflected variations and inconsistencies across participants.

\section{Reasons for Forging Formal Relationships}

Almost all support partners expressed motivations for initially forging formal relationships with RSOs. "I definitely had reasons to do this," 48-year-old Tabitha asserted, “and it's why I'm doing what I'm doing - supporting Brian.” In the words of Taylor, who met her spouse, a RSO, on eHarmony, an online dating website, after he offended, "Something certainly did cause all this, my decision to support Jeremy." However, a belief that no one else was willing to serve as support partners for RSOs was the most common explanation. As stated by 75-year-old Wendy, whose son was convicted of sexual assault, "His dad isn't going to do it. His brother isn't going to do it. So, guess who's got to do it?" In a similar vein, Melanie, a mother of a RSO, voiced:

The fact is I had to do this. Nobody else gives a damn about Donald, especially with what he did. He made a mistake, sure, but other people don't see it that way. I'm the only person he can really talk to. If I didn't support him through this, who else would? There's nobody else.

Another support partner, Wallace, shared a similar perspective:

Nobody who'll support poor Ricky. You think his other relatives would do this? No way. Ricky, he got caught up in some bad stuff, but I had to be here for him. Others may say, "It's not happening." I couldn't do that. 
At the same time, numerous support partners were motivated by a fear that adverse events would be more likely to transpire in the lives of RSOs, if they did not agree to serve in such capacities. "I was concerned," admitted 70-year-old Tara, whose son was a RSO, "because bad things could happen to my boy, and bad things could happen more so, without me there." As Lauren, a clergywoman in her church, confessed:

At first, I wasn't sure I had time to devote to Nathan. Then I thought, "He's my son!" Then after that, I thought, "He's really got it tough!" He's not the problem. The problem was, I thought, "What if I'm not there for him?" I was afraid he's just going to face worse things. Sex offenders just don't fare well in society.

Interestingly, as made evident by Lauren, these participants were not fearful of the actions of RSOs, such as future criminal behavior. Instead, support partners were frightened by the perceived responses of society to RSOs. "I was worried that the community to which Ferguson was returning would harm him," muttered Hope, a dental assistant, "because my son is a known sex offender." Such alarm regarding society's reception of RSOs spurred participants on to establish formal relationships with them, because they believed doing so would minimize the impacts of negative reactions from society.

For instance, among these support partners, housing was a near-universal concern that prompted a willingness to support. Specifically, several participants believed that RSOs would not have access to shelter without them. As Wallace, who religiously paid his nephew's rent on the first of each month, expressed, "I was worried that Ricky would be homeless, if I wasn't around." In the words of Theresa, "Jack would be out on the street, if I didn't do this for him. No landlords are going to rent to somebody on the registry." The 46-year-old telemarketer allowed her brother, a RSO, to stay in her home, after he was unable to secure a residence: "I had to do it. Let him in my house. I agreed 
to support him, because I was scared that he'd be living under a bridge or something. I'm making the housing a nonissue.” Other support partners felt that adequate housing accommodations for RSOs were otherwise improbable. "Listen," requested Susan, whose brother was a RSO, “Chris couldn't get a real place to live without me. He'd still be living in that dumpy room in a high crime area." Similarly, Max contended, "My brother, the offender in this case, would be living in some crap hole, if I didn't support him and become his support person. I'm making things less painful for him."

A majority of support partners saw employment as another barrier that faced RSOs in society, and such consequently provided the impetus for forming supportpartner-sex-offender relationships. "He doesn't work, because nobody will give him a job," explained Frank, whose son was convicted of unlawful transaction with a minor, “and I needed to support him personally, to ensure that the whole situation doesn't get worse." The 85-year-old retiree believed that, by being a support partner for his son, he would alleviate some of the pain associated with unemployment. Gus, a support partner for his wife's brother, attributed his initial decision to serve in such a role to having awareness that RSOs likely struggled to find work:

My brother-in-law's got no job. No job whatsoever. It's frustrating, but I get it. He's a registered sex offender. I thought, "If I do this, maybe he'll see I'm on his side, and he'll have more confidence." This assurance may help him talk to more employers, and maybe somebody will give him a chance. This would reduce the hardships he's dealing with.

Further, many support partners were driven to forge formal relationships with RSOs because they felt that such individuals, in spite of their social standings, had redeemable qualities. Some participants believed that RSOs were intelligent individuals. Hubert, a high school graduate, who regretted never attending college, stated, "My son 
was not thinking, but he is incredibly smart. He's got a sharp mind. It's worth saving." In the words of Megan, who served as a support partner for her brother, "When we were in school, he would always get better grades than me. He's a smart guy, sometimes too smart, but it tells me that he can do better and should be supported." Other support partners expressed that there was something inherently virtuous about RSOs, despite their statuses. This was particularly true among support partners who were married to RSOs. As Maria pointed out, "I decided to support him, because he's a good person. He really is." In a similar vein, Erin weighed her husband's statutory rape conviction against her knowledge of him since the offense:

I met him after he committed a sex offense. What I know of him is good. He is good. He is a sweet, kind-hearted man. I know his crime is bad, but what he is to me, it's good. It's nothing to do with his earlier life. He is good now, so I can help him.

And yet, a few participants who were not married to RSOs held consistent views. As Lauren acknowledged, "My son has high moral standards, but made some bad decisions. This is another reason why I support him." In the words of Chelsea, "He may be my exhusband, but he is an exceptional man to me."

Almost without exception, support partners provided the rationale behind initially forging formal relationships with RSOs. The most frequently expressed reason was a feeling that no one else was willing to do so. Numerous participants, too, were motivated by a fear that society's harmful treatment of RSOs would more strongly impact their loved ones if they did not become their support partners. In the eyes of these support partners, their initial readiness to serve in such capacities was often predicated on the assumption that obtaining housing and employment were obstacles for RSOs. Moreover, a belief that RSOs had redeemable qualities, such as intelligence and inherent goodness, 
was the driving force behind many participants' decisions to be support partners at the outset.

\section{Explanations for Maintaining Formal Relationships}

Beyond explaining why they initially formed formal bonds with RSOs, a majority of support partners expressed motivations for preserving such relationships. Although initial reasons for establishing such associations largely focused on RSOs, explanations regarding the maintenance of these relationships centered on support partners. "It's funny," laughed Nicole, "supporting my husband was first about him, but now it seems to be about me." As stated by Traci, a mother of a RSO, "I did it for Nelson, but as time goes on, I partially do it for myself." Specifically, the ability to become closer with RSOs was often perceived to be a rewarding outcome of continuing formal relationships. “There's less distance between us now," declared Tara, "and I get to know him better each day." Similarly, Max voiced, "My brother and me, we didn't see each other much before this happened. I've found that now we're much closer, in a strange kind of way." Spouses of RSOs, however, were the most likely participants to share this view. Patty explained how she and her husband became more intimate:

Now that I've been doing this with Steve for a while, being his supporter, the two of us have really become one. I guess what I mean is, there is a stronger connection now. I know him more. I know what made him do what he did, and I feel so much more like we understand each other.

Duration of marriage apparently did not impact this phenomenon. Taylor, who had been married for one year at the time of her interview, excitedly mentioned, "I know my hubby much better now, and I can say that I feel that I understand him and what he went through, when I didn't before.” By the same token, Maria, who had been married 
for 20 years at the time of her interview, spoke of her newfound intimacy with her husband:

I've been married a long time. When tragedy struck, I went on supporting him, even when others told me not to. Then, I guess I was given the husband I always wanted. The bond we have now is much stronger.

Besides feeling more connected to RSOs, support partners occasionally explained that they maintained support-partner-sex-offender relationships, because such associations offered them a sense of meaning. Like a few participants, Lauren believed that "helping gives me a purpose in life." Similarly, as Frank, who was absent for most of his son's childhood, stressed:

There's nothing else I'm doing that is as important as being there for my son. It's a job that carries a lot of weight. I want to do something meaningful for my son. I was not there early on, but now I am doing something that shows him I care.

A majority of support partners explained why they decided to continue their formal relationships with RSOs. Although the establishment of the support-partner-sexoffender relationship was often about external issues related to RSOs, as formal associations evolved, participants chose to maintain such arrangements for internal reasons. In other words, support partners clearly got something out of the associations, too. The ability to become closer with RSOs was the most widespread reward of preserving formal relationships, and this was an especially common incentive among spouses, regardless of marriage length. In addition, a minority of support partners said that formal relationships with RSOs afforded them a sense of worth, prompting them to continue participating in such associations. These latter motivations, which explained why participants maintained formal relationships, may be thought of as benefits of being support partners. Thus, it is appropriate to also consider the costs of taking on such roles, 
in order to provide a more balanced understanding of support partners' experiences.

Chapter V examines participant narratives in this context. 


\section{CHAPTER V}

\section{COSTS OF SERVING AS A SUPPORT PARTNER}

The motivations revealed by support partners outlined in Chapter IV focused on the perceived advantages obtained from the support-partner-sex-offender relationship. As a complement to that section, this chapter describes the reported costs, or disadvantages, of being a support partner. More formally, this section asks, "what are the costs of serving as a support partner of a RSO in the community?" By using participant narratives, this chapter sheds light on the potential negative consequences associated with accepting and developing a close association with a widely reviled type of lawbreaker - a $\mathrm{RSO}$ - with hopes of finding feasible remedies to ensure adequate social support.

Analysis of interview data revealed that there were five primary costs that participants experienced in their roles as support partners of RSOs. These negative ramifications included loss of relationships, deterioration of relationships, isolation, harassment, and stigmatization. Although these costs, which were believed to be the result of their associations with RSOs undergoing treatment, were widespread, the perspectives of support partners regarding such negative consequences reflected variations and inconsistencies across participants.

\section{Loss of Relationships}

All support partners in this study described costs that stemmed from their close associations with RSOs. The most prominent theme across participants, however, focused on their reported loss of relationships. Almost without exception, support 
partners believed that at least some relationships with other individuals disappeared, after agreeing to help RSOs complete treatment and successfully reenter society. As Rupert, a 49-year-old business owner, explained, "Because I chose to support my son after his offense, some other people in my life decided to leave." Similarly, reflecting on how several acquaintances no longer returned her phone calls, 50-year-old Candy, whose son was convicted of possessing child pornography, acknowledged that "relationships with other people are drying up fast, as they learn that I'm helping Miguel with his issues."

Specifically, friends were the most common individuals said to have completely stopped interacting and otherwise communicating with support partners. "I've lost a couple of friends," confessed Chelsea, a 43-year-old mother who served as a support partner for her ex-husband, “because they couldn't understand why I would continue to help a man who committed a sex crime." However, newer and less intimate friendships were more likely to vanish, once participants formally established themselves as support partners of sex offenders undergoing treatment. As stated by 70-year-old Edith, whose grandson was convicted of first-degree sexual abuse, "Friends I met recently at Bingo do not talk with me now. They aren't as close to me as my other girlfriends." In the words of Wallace, who retired as a computer programmer shortly after his nephew was featured on NBC's To Catch a Predator, a reality television series devoted to seducing and subsequently apprehending sex offenders through the Internet, "Casual buddies of mine at work really didn't stick around, whereas my strongest friendships really stayed the same, even when it was well known that I was his uncle." 
And yet, it was not unusual for long-standing and close friendships to completely die out, as well. Like many support partners, Maria, a 57-year-old nurse, described losing a lifelong friend:

One of my best friends I've had since the $4^{\text {th }}$ grade is a prosecutor. I called her about my husband's offense, and now that friendship is gone. It's gone! It's instantly gone! She called me "one of those women" who takes the man over the child. Pretty much she said she could never forgive my husband. Because I keep trying to help and be there for him, she said she would never want to associate with me again.

Another participant, Tabitha, shared a similar perspective:

My two best friends since I was 14, they had concerns about my continued involvement with my husband after his sex offense conviction. I tried to tell them I am trying to help him with moving on and looking toward the future, making sure it doesn't happen again, but it didn't seem to matter. The fact that I stuck around with him made them mad. We don't talk anymore.

At the same time, for many support partners, relationships with family members also abruptly ended, following their commitments to help RSOs complete treatment and successfully reenter society. Traci, a 52-year old real estate agent, explained how she lost her daughter:

After being a support person for my son, my daughter responded negatively. My daughter is now 19. She won't come and stay with us at our house any longer. She said that she couldn't stay with us anymore, that it creeped her out to be with me. I haven't heard from her since.

Interestingly, Traci's son was convicted of possessing child pornography, and her daughter allegedly was never victimized. In a similar vein, 29-year-old Ruby, a newly married college student, who served as a support partner for her husband, was purportedly disowned by her entire immediate family:

My adoptive mom, she took care of me from the time I was eight, all the way up to about two years ago. Because I still talk to Bob, she won't have nothing to do 
with me. The people I call my brothers and sisters, they're not allowed to talk to me, because they get in trouble by our adoptive mom and dad. My adoptive dad said he will leave my adoptive mom if she talks to me, because I'm with Bob and supporting him. My father, our relationship is no longer. He can't believe that I would see Bob as a good person and not see him for the monster supposedly is. He doesn't understand how I can upgrade Bob and tell him he is a really great guy. No matter what, Bob's a sex offender and shouldn't be helped.

Loss of relationships was a near-universal problem identified by support partners, as they attempted to help RSOs reintegrate into society and become law-abiding citizens.

Although newer and more distant friendships were the most likely to become extinct, friends and family members who represented long-standing and more intimate connections frequently terminated their relationships with participants who decided to support RSOs.

\section{Deterioration of Relationships}

Apart from losing relationships with friends and family members, deterioration of relationships was identified by almost all support partners as a cost of helping RSOs. In the eyes of these participants, the quality of associations with other individuals worsened, and they attributed this negative consequence to their close interactions with RSOs.

"With my doing this, supporting my grandson," Doris declared, "my relations with others are declining." As with loss of relationships, newer and less intimate associations were the most prevalent type to be impacted, once support partners formally established themselves as confidants of RSOs. In particular, individuals who lived in close proximity to participants were often viewed as acting differently toward them. As 50-year-old Max, a business owner, who served as a support partner for his brother, pointed out, "I see my neighbors, and things are different. Their reception of me is not the same. If they were going to invite me over for a pig roast, I'm not getting those invites anymore." Likewise, 
Traci articulated how a flourishing friendship with a female neighbor quickly deteriorated:

I talked to the one neighbor. She and I kind of hung out a little bit, but now not much at all. She still says, "Hi." She's nice, but you know, we don't get together anymore. Not after I decided to support Nelson with treatment and getting better.

Edmund, a father of a RSO, echoed this experience:

I live in a small apartment complex. Don't talk to many people, other than Derrick, the one that lives upstairs. We were becoming friends. He used to come to my apartment all the time. Then with dealing with my son, he stopped coming to my apartment. He's kind of what my mom would call a "two-faced person" now. He isn't the same.

Casual friends and other contacts were also frequently reported to be no longer the same, after learning of the close interactions that support partners had with RSOs. "I'd go to festivals in the summer," recalled Nicole, a spouse of a RSO, "and usually you see people and talk with them, but most recently, there were some people there that went the other way." Although discouraged, the 62-year-old school teacher initially dismissed the cold reactions she received that night, until it happened to her again one week later:

I went to a couple of things where I saw some old friends, but there's clearly now the elephant in the room. If they didn't avoid me, they were asking about how everyone was, except Marvin. And to me, my sticking by his side, that's the elephant in the room and why they were acting strange.

By the same token, Lynn, a spouse of a RSO, described the altered behavior of a female coworker, after discovering that she still supported him:

This one girl at work, she just wanted to know what happened and all this, and why I'm still around him. I'm thinking, "If you want to know, go look on the Internet." Well, of course she did. We used to talk a lot, but now sometimes she'll talk to me, sometimes she won't. I don't think she likes me still being with Bill. 
Further, among a majority of support partners, long-standing and close relationships were not exempt from undergoing negative transformations. "Since I've been supporting Matthew," Maria announced, "my own family no longer offered to let me come into their homes." Like many support partners, Ruby was surprised by her once-loyal friend's recent actions:

I couldn't believe it. My friend, Stephanie, who was so close to me, when people find out who my husband is and that I support him, she starts getting snickers, and she's gone for a couple of months. She's ok for a while, but when everybody else starts judging, she's ready to go. Our relationship is not as strong as it used to be, and she's in-and-out.

Nearly all support partners believed that at least some of their relationships with other individuals weakened, after agreeing to help RSOs complete treatment and successfully reenter society. The most commonly diminished associations were those with neighbors and other less intimate individuals. However, the strength of connections with individuals closer to support partners also faded.

\section{Isolation}

Isolation was another cost described by a majority of support partners, after they decided to help RSOs complete treatment and successfully reenter society. According to Felicia, whose son was convicted of statutory rape, "I wanted to do what I could for Ryan. I think because I have, I've been cutting myself off from the rest of everybody." Felicia's efforts to intentionally distance herself from others characterized the experiences of numerous participants who agreed to serve as support partners. Amelia's comments were also congruent with this phenomenon. "I feel like I need to get away from people," she uttered, "and it's been that way since I've been so close to my exhusband and involved in his recovery." 
Specifically, these support partners often limited their activities in the communities in which they lived, with a specific focus on avoiding other people. "We have definitely isolated ourselves," asserted Nicole, including her husband in the discussion, "and we have rarely gone to social events, so we evade people. Only funerals, if you want to call that being social." She continued, however, noting that "when alone, I also do not want to be around others." Like many support partners, Traci did not fully comprehend why she actively stayed away from other individuals:

I have become secluded. I mean, we don't go out, I don't go out, we can't face anybody... We don't want to run into anybody ... I'm not sure why, but I feel with everything that happened with my son, it's made me less outgoing.

In a similar vein, 72-year-old Colleen, who served as a support partner for her son, admitted:

I don't get out like I used to. Some of that is my age, some of it isn't. It's Randy, it's since all this happened with him, and I just find that I'm retreating from everything. I guess that's just how it is now. I don't want to be around others.

A minority of support partners went to extremes to escape interactions with community members. Ruby discussed her well-thought-out plans for those instances when she and her husband needed to leave home:

I only go out in public during school hours. Town's quite dead. We can go and do anything we need to do then, and 15 minutes before school lets out, people are going to be coming, and it's a whirlwind of hurt that's coming. So, we get back before then.

At the same time, in their attempts to isolate themselves, numerous support partners found their homes to be places where they could be sheltered from encounters with other individuals. With the home as refuge, 47-year-old Gloria, a mother of three, organized her social life around events behind closed doors: 
We make sure we have family nights at home. We're having fun, but at the same time, we're staying distant from everybody... We live in a rundown, trashy dump, but it's home. We know that when we go home, that's our safe place.

In the same way, Sheryl, a 45-year-old spouse of a RSO, planned the future with her new husband, with every intention of remaining within the confines of their country bungalow:

We stay home; it's safe there. I don't want harassment, throwing stuff, or mean words, so we're probably never going to move... Harry's got time off, so we might have a stay-cation. We have lots of plans that are going to keep us grounded and close to home. You can't go very far if you have a big garden.

In the eyes of support partners, isolation was another cost of helping RSOs. This selfimposed seclusion included limiting public activities, structuring time to interact with fewer individuals, and utilizing personal residences as refuge.

\section{Harassment}

Following the establishment of their formal relationships with RSOs, many support partners reported that they experienced harassment. In some instances, such hostile actions directed at participants came from known community members. "I promised Daniel I would help him get through all of this," 44-year-old Heather expressed, "but other people in the city, who I know, are constantly trying to intimidate me." As the sister of a RSO, Heather knew life would be tough, but never imagined how being her brother's support partner could expose her to such cruelty from familiar individuals:

I am honestly shocked by the reactions. I know these guys. I'm just standing by my brother. He made a mistake, but is moving on with his life. They don't understand that. I have people throwing things at my house, and notes left on my door, telling me I must be a sex offender, too. 
A statement from Ruby, who faced persistent torment, best summarized the multitude of ways that support partners in this study were harassed by known community members:

I've had people call me "sicko," a "chomo lover," and "no better than him for loving him." They say I will let Bob do anything that he wanted to do. I am just as equal to him for being with him, I am as sick as he is, and I would probably help him commit sex offenses. A common one is that I'm a "bad mom." I'm "retarded." I've been threatened for loving him. I was told if I go see a former friend of mine, he's going to beat me with a baseball bat. Bob's daughter had a play during summer, and he was gone. I went in there, and I could hear the snickering and all that. They were sitting right in front of me. "Oh, look who it is! I wish she would just go away! Why is she even here?" And I know it's because I'm helping Bobby.

By the same token, Nicole described the antagonistic actions of former friends who lived nearby:

The neighbors won't even look at me now. My husband and I were working in the yard in this shared flower bed, and I was standing with the trashcan on the driveway. The neighbors came out and told me to "get the hell off" of their property.

Sometimes such harassment came in less direct forms. Traci explained her experience with an aggressive neighbor:

The one neighbor has been causing a lot of problems for me. After seeing my son and I out together, the neighbor sat outside my house. My nephews live down the street, and they said, "Why is your neighbor starring at your house like that?" I'll never know what he was up to, but he just glared at me, so I was worried about what he was planning.

Other participants were not always aware of the source of harassment. In the words of Melvin, who received a threatening voice message on his cell phone hours after being out in public with his father, "They basically said, in frightening language, that they wanted to cause me bodily harm for still talking with my dad." Similarly, Janice spoke about a mystery man vandalizing her property. Although the 53-year-old never 
caught anyone in the act, she remarked that "somebody, probably a guy, hit our mailbox and spray painted it." Janice attributed this destruction to her openness about supporting her husband, a RSO:

I think somebody doesn't like that I'm doing this for him. That I'm supporting him, that I'm around him, that I say so. I'm just helping him do better. I shouldn't have to deal with my stuff being ruined, for associating with somebody who is known as a sex offender.

More common, however, was the view that criminal justice officials incessantly troubled support partners. It should be noted that all participants in the present study were supporting RSOs, who were under some form of community supervision while attending treatment, which likely increased contact between support partners and criminal justice officials. Like numerous support partners, Lynn's words illustrated this phenomenon:

Once I started supporting my husband, the cops would drive slowly by our house, at least a few times a day. This lasted several months. When I would be outside, they would be sure to tell me that a registered sex offender lived where I was standing, saying I should be careful. I tell them, "He's my husband!" They become hostile with me, try to tell me I should be inside the house, and simply drive off. I'm not the one who should be under the microscope.

As was the case for Lynn, participants who lived with RSOs were confronted with the most persistent torment. An example from Tara's interview further highlighted this reality:

Probation and parole came in my house. I had pictures of my family on the walls. My granddaughter, when she was small, she's 20 now, and the other granddaughter. They said I had to have them taken away, because I wasn't allowed to have them out. They did that to me, and I thought that was kind of puny. That upset me. I didn't like it because it's my home and my pictures. They weren't bothering anybody. I don't think pictures of clothed children are going to make an evil person out of my husband. 
In a similar vein, Tabitha, revealed how one probation and parole officer constantly subjected her to hostile remarks:

I'm essentially a single mother, and I've been on my own. I haven't had any help, and my husband can't really help with all of his restrictions, and that is fine. I'm proud of being able to do everything myself. But the probation guy made a comment about my grass being too long, that I need to cut my grass. Oh my God! I'm thinking, "Why don't you tell him that my gardener is on vacation with my maid, and if it bothers him that much, he can come over and mow my grass?" I was livid. I was livid that he would even make a comment about me. He's always doing that, saying negative and rude things to me for no apparent reason.

And yet, several support partners who did not live with RSOs allegedly received regular threats from criminal justice officials. Erin, who served as a supporter partner for her husband, was unable to live with him, because she lived 866 feet away from a daycare facility. The 24-year-old owned her own home, and her disability prevented her from staying in the cockroach-infested room that her husband was forced to rent. Although Erin received regular doses of harassment from local law enforcement, the most striking episode unfolded at a state university:

My husband and I were in the school library. He can't have any female friends at school. If they're a student and they're female, he can't have relations with them or be friends or whatever. He was working on homework, and I see these two police officers. The officer was like, "Andrew, can you come with me?" And I'm like, "What's going on?" The officer was like, "What's he doing on the computer?" And I was like, "He was doing homework on Microsoft Office. He was doing homework." He was like, "Ma'am, are you a student here?" I was like, "No, I'm his wife." So the two officers suddenly became less concerned about my safety, but wanted identification. I showed them my license, and they started saying I needed to get out of the school, since I wasn't a student.

Harassment was identified by many support partners as a cost of helping RSOs.

Threats and hostile actions often originated from individuals known to participants, but could not always be attributed to familiar persons. The most common source of 
harassment, however, was criminal justice officials, and support partners who lived with RSOs faced the most persistent suffering from these individuals.

\section{Stigmatization}

Beyond the loss of relationships, deterioration of relationships, self-imposed isolation, and harassment, numerous support partners felt that they were stigmatized, as a direct result of their close associations with RSOs. In other words, participants believed that they were described, labeled, and regarded in certain ways by other individuals to show strong disapproval, because they served a supporting role for a group of highly defamed criminals. According to Patty, whose husband was convicted of aggravated sexual battery on a 13-year-old female, "It's the strangest thing, but because I'm with Steve and encouraging his treatment, the contempt people have for him is transferred to me." Taylor similarly realized, "Yes, my husband is a marked man, but I'm also branded now for accepting him and opening my home to him."

In the eyes of these support partners, this courtesy stigmatization (Goffman, 1963) - whereby marks of disgrace were assigned to them by others in society for maintaining intimate relationships with RSOs - was almost always the most powerful cost. As emphasized by Michelle, "My being labeled through Henry is the most damning consequence of supporting him." The strength of this stigma was occasionally credited to its apparent ability to explain all of the aforementioned costs that came with helping RSOs. "Because of my labeling," Wendy conveyed, "I have all of these problems with relationships and harassment." Dominic, a 58-year-old insurance salesperson, was a father and support partner of a RSO. "That's why I'm dealing with all of this shit," he remarked, "because of the stigma I have now for being there for Paul." 
And yet, for many participants, articulating the impact of being stigmatized was nearly impossible. Instead, these support partners focused on describing in some detail their courtesy stigmas. Some participants felt that they were viewed differently, after deciding to serve as a support partner. "When I go out in public," Ruby stated, "I feel like I'm considered unusual, and I get stared at. It's like I've got 3 heads and 5 legs." In the words of Melanie, who reflected upon her professional and personal relationships, "People don't see me the same anymore. People see me as a monster." Max, too, was confident that he had become stigmatized, especially after offering his brother a place to say in his home:

The disgrace that is thrown on you by having a brother on the registry is devastating, it's depressing, and I don't see how people get through it. You're red-flagged, you're walking around with a flag on your head. You really are no longer the same to other people.

Other support partners not only believed that their identities were spoiled, but they also began to question their personal characters. "It's like everyone thinks I'm a dirty person," Amelia remarked, "so maybe I'm not such a goodie-goodie anymore." Similarly, Heather complained:

It sucks because there is a stigma and a label attached to my brother and also by association to me. It's like, "Ew, you have a pedophile in your family, and you must also be a pedophile." I never thought of it like that before, but I guess that's what happens when you get in deep with a hated person. Could I really have the potential to do something like that?

Many support partners saw themselves as stigmatized individuals, because they accepted RSOs and offered them support. Although their courtesy stigmas were almost always considered to be the most powerful cost associated with their roles, the rationale behind this feeling was not always clear. When the influence of stigma was articulated, 
participants believed such stigmatization to be responsible for loss of relationships, deterioration of relationships, isolation, and harassment. Support partners who experienced stigma often reported that they were viewed differently than in the past, and others even began to question their moral compasses. How participants managed their stigmas is the focus of Chapter VI. 


\section{CHAPTER VI}

\section{STIGMA MANAGEMENT}

The costs of serving as support partners of RSOs were discussed in Chapter V. Interestingly, almost without exception, participants believed that courtesy stigmatization was the most powerful negative consequence of the support-partner-sex-offender relationship. After perceiving themselves as stigmatized, numerous support partners described techniques that they used to manage a devalued aspect of their identities - their close associations to RSOs. This chapter examines how participants survived the stigma through attempts to control or hide it. Successful strategies to manage stigmas, once identified and subsequently adopted, may help future individuals close to stigmatized persons minimize unpleasant ramifications and offer stronger support.

Analysis of interview data revealed that there were two primary sets of management techniques that support partners utilized, in order to handle their courtesy stigmas. One group of themes concerned strategies used by participants who believed they were marked with visible stigmas, whereas the other group of processes involved approaches that were selected to address perceived invisible stigmas. In terms of support partners who perceived carrying visible stigmas, acknowledgement and differentiation of loved ones constituted the most popular methods. With respect to participants who perceived having invisible stigmas, their efforts were focused on passing as individuals who were not intimately associated with RSOs and covering their formal relationships with them. 


\section{Dealing with Visible Stigmas}

A majority of support partners felt that they were marked with visible stigmas. Among these participants, stigmatization was believed to be readily apparent to others. Indeed, Goffman (1963) referred to these individuals as "the discredited," as their stigmas were discernible and known. "I am labeled because I interact with my son," Rupert contended, "and this label is known to others." In the words of Candy, another parent of a RSO, "Miguel is stigmatized, and as a result, so am I. Everyone knows that I'm the mother and supporter of a sex offender." Specifically, these support partners asserted that their stigmas were exposed to the world, because their loved ones were obligated to register as sex offenders and identified as such on publicly available, online registries. "It's my brother who messed up, but the registry associates him with me," Megan commented. She continued:

I can't hide. My stigma is the stigma of my brother. I'm accepting of my brother, so I must be just like him. My label is known to others, because everyone knows that Zachary is a sex offender, being on the registry. Since they know this about him, they know he's my brother, so I'm also labeled.

Similarly, Wendy commented, "Everyone can see me with this label. My son's on the registry, and they know he's my son. We're connected." This showed that sex offender registration indirectly impacted the lives of many support partners.

Although not articulated as reasons for having their stigmas uncovered, it is important to note that these participants either shared a surname or home address with their loved ones, which could have made sex offender registries obvious threats to their identities as mechanisms of exposure. Last names or home addresses, which are items readily found on sex offender registries, if matching, would reveal their close associations with RSOs. Support partners who perceived having invisible stigmas (discussed below) 
did not share surnames and rarely had the same home addresses. In this way, participants who saw themselves as the discredited believed that sex offender registration not only made the public aware of their loved ones, but also revealed who they were - support partners of RSOs.

\section{Acknowledgment}

Support partners who perceived having visible stigmas utilized two distinct strategies to manage their spoiled identities. The most common stigma management technique was acknowledgment of their courtesy stigmas. These participants felt that it was best to own up to their close associations with RSOs. As stated by Frank, "I just have to tell people that my son is on the registry, and he is my son. I make sure to say that he made a mistake, he's my blood, and I'm helping him move forward." In a similar vein, Melanie recalled how she coped with her discredited status:

I quickly realized that, in order to get through the day, I'd have to be upfront about things. I told people I knew and strangers sometimes, too. I told them, "Yes, I'm related to someone on the registry, and I do help them with treatment." I've found that I need to just recognize the situation.

Like many support partners, Melvin explained the value of openly addressing his stigma:

You got to let them know. There's no use in hiding it, because my dad's on the registry. If I hide my association to him, or my relationship to him, I feel tension when I am around other people. This is not a good feeling. So, to avoid being uncomfortable, it's better just to be outright with the information.

Acknowledgment of their stigmatization through communication with other individuals allegedly relieved the strain otherwise experienced in interpersonal exchanges. This acceptance of stigma allowed support partners to release an obvious truth about their identities. 
When these support partners proactively revealed their formal arrangements with RSOs to other individuals, they often believed that their stresses regarding such disclosures subsided, because they no longer had to wait around for other individuals to broach the difficult subject. As Frank mentioned, "My worry over telling people about helping my son ends, and I don't have to wonder when it's going to come up." The finding that these participants felt defenseless against exposure and feared being "outed" before acknowledging their statuses was consistent with the experiences of RSOs reported in prior research (Burchfield \& Mingus, 2008; Levenson \& Cotter, 2005a; Levenson et al., 2007; Robbers, 2009; Tewksbury, 2004, 2005, 2012, 2013; Tewksbury \& Lees, 2006a, 2006b; Tewksbury \& Mustaine, 2009), where persistent feelings of vulnerability were among the most common problems facing registrants. It appears that RSOs and their support partners share apprehensions regarding disclosure of statuses.

At the same time, acknowledgment of courtesy stigmas helped to offset strain experienced in interpersonal exchanges, by allegedly making participants appear honest and potentially trustworthy to other individuals, in spite of their discredited social standings. In this manner, openness was said to balance the negative effects of stigmatization. This was congruent with earlier studies on stigma management, where open recognition of visible stigma improved public perceptions of the discredited (Davis, 1961; Hebl \& Kleck, 2002; Hebl \& Skorinko, 2005; Singletary \& Hebl, 2009). A recent qualitative study (Evans \& Cubellis, 2014), where RSOs commonly perceived honesty about their statuses to be an effective tool for achieving credibility in social encounters, was also consistent with the idea of acknowledgement being beneficial to stigmatized individuals. Support partners holding this view attempted to display such desirable 
qualities, in order to compensate for their purportedly spoiled reputations. "If I don't talk about my stigma in the first few minutes of conversation with someone," Colleen declared, "they're going to think I'm trying to avoid the issue altogether." As a mother of a RSO, she believed that nearly everyone knew of her close relationship with her son and did not want other community members to think she was dishonest:

I'm not going to be viewed as a liar or as someone who can't face reality. When I tell people about my relationship to Randy and that I know that I'm judged for it, this shows that I'm not evading and can be trusted, even though they might not have thought so at first. I'm being honest, and this helps chip away at the bad feelings people have.

These support partners believed that publicly accepting and freely expressing devalued aspects of their lives - their formal relationships with RSOs - reduced anxiety surrounding interactions with others, as such allowed them to present themselves in a positive light, which helped to diminish the influence of their stigmas.

\section{Differentiation of Loved Ones}

Another strategy utilized by support partners was to distinguish their loved ones from stereotypical conceptions of RSOs. Among these participants, efforts were made to share specific information about loved ones, in order to differentiate them from widely held, often inaccurate, and always negative images of RSOs. "Ricky, he's slow, his IQ is extremely low," insisted Wallace, "and he just thought he was making a friend." This uncle of a RSO noted that this was an important detail that should not be ignored:

I make sure to tell them that. That Ricky's mind is not like everybody's. They thought he was in the autism spectrum. I tell them this, to convince them that my nephew was not a predator on children. He's not unforgiveable.

As was the case for Wallace, these support partners almost always made certain to portray their loved ones as individuals who did not ruthlessly exploit children. 
Interestingly, such approaches were reminiscent of the behaviors of RSOs found in Tewksbury and Lees' (2007) research, where nearly all of the 22 registrants distinguished themselves from those whom they saw as "real criminals," "dangerous," and "sexual predators" (p. 395). By extension, support partners were then able to explain their support for RSOs in more socially acceptable ways, describing themselves as willing to help only individuals who deserved it - those who did not ruthlessly exploit children. As Wallace continued, “I say I support him, and I don't support a person who preys on children." Hubert, whose son was convicted of sexual misconduct with a prostitute, sought to similarly distinguish his son from other RSOs:

My son was in the military. He was serving his country. I make sure people know that. They need to know he was overseas, and he and some other soldiers got involved with a prostitute. A man away from home has needs. How was he supposed to know that she was underage? She told him she was legal. She looked legal. I tell them that he's my son, but he was soldier away from home. He wasn't a menace to society.

Hubert, too, later mentioned that he would not "support a true menace." Like some participants, however, he not only attempted to convince others that his son was not deliberately targeting children, but also emphasized his son's other desirable qualities in the process. This was done to further bolster the positive impressions of RSOs created by support partners. This reflected the strategies of a minority of support partners, who engaged in compensating, or making up for their loved ones' shortcomings by stressing their positive attributes.

Portraying the personalities of RSOs and the circumstances surrounding their crimes in a more tolerable light was critical to effective differentiation. Support partners adopting this strategy believed that it allowed them to adequately separate their loved 
ones from violent predators who intentionally attacked children, a despised group of criminals considered to be beyond mitigation and redemption, which increased their loved ones' chances of acceptance. In turn, their support of RSOs was viewed as more justifiable, because such support was aimed at individuals who were more likely to be seen as worthy of assistance.

Spouses of RSOs were the most likely participants to use differentiation. "It's important for me to be able to defend my husband," announced Maria, "because then the shame comes off of me, when people understand who he really is." In the words of Erin, "I don't believe Andrew is a real sex offender, and I tell people this upfront. I wouldn't be here if he was a monster." Because they saw themselves as more intimately connected to RSOs through marital links, spouses felt that they needed to justify why they would "stand by their men." By pointing out that their husbands did not viciously attack children, they believed that other individuals, particularly other married women with children, who predominately made up their social networks, would be more likely to understand their decisions to remain married and provide support. As Tabitha, whose husband was convicted of possessing child pornography, explained:

I tell them that I've known Brian for 20 years. Never in that time has he given me any indication that he would hurt a child. I tell them that he wouldn't hurt a fly. He is a sex offender, but he did not offend against an actual child. He had a pornography addiction, and he got into some stuff he shouldn't have. I explain that he would not ever hurt a real child and that children are safe around him. I say that it would be a different story, my supporting him, if he assaulted children. I need people to know this about him, because I'm so close with Brian, as his wife. We live together and have children together.

Like other spouses, Tabitha saw her bond with her husband as particularly strong, because she was married to him. As a result, she felt that establishing her husband as 
different from traditional notions of sex offenders, while emphasizing that he did not physically assault children, would make her decision to stay with him more acceptable, especially to other women with similar backgrounds.

\section{Summary}

More than one-half of support partners perceived themselves as carrying visible stigmas, and they attributed this reality to their loved ones' statuses as RSOs. That is, participants believed that their stigmas were revealed to society at large, because their loved ones were listed on publicly available, online sex offender registries. It is important to note that these support partners either shared a surname or home address with their loved ones, which likely explained why they felt that sex offender registries uncovered their stigmas. The most frequently used method for managing perceived visible stigmas was to publicly acknowledge such marks of disgrace. This technique allegedly relieved the tension otherwise experienced in interpersonal communication for two reasons. First, participants no longer had to hold off for other individuals to broach the difficult subject of their statuses, and second, this made them feel that they were effectively presenting themselves as candid and trustworthy, which counteracted their stigmas. Other participants intentionally distinguished their loved ones from stereotypical conceptions of RSOs, by describing loved ones' personalities and crime stories in a more tolerable light, so as to offer additional information that allowed for more favorable judgments. Specifically, support partners attempted to distance loved ones from images of violent predators who intentionally targeted children, because this was believed to increase their loved ones' opportunities for public acceptance and subsequently shape community perceptions of their support as justifiable. In doing so, 
they sometimes engaged in compensating, whereby they emphasized their loved ones' other desirable qualities in the process, to make up for their loved ones' transgressions. The tactic of differentiation was especially common among spouses, who overwhelmingly felt they had a vested interest in identity management, as they saw themselves as more intimately connected to RSOs through marriage. They believed that other individuals, particularly other women with children, would be more likely to understand their support of their husbands and accept them once they understood that children were not directly assaulted.

\section{Dealing with Invisible Stigmas}

Unlike a majority of support partners, some participants felt that they were marked with invisible stigmas. These support partners believed that one devalued aspect of their identities - being confidants of RSOs - was not readily apparent to others. "I've got this mark on me, but many people don't know it," Tara confessed, “and I'm walking around with a scarlet letter on me, but nobody can see it." Tara and other support partners who saw their stigmas as invisible were regarded by Goffman (1963) as "the discreditable" or individuals whose stigmas were unknown and potentially able to be hidden. It is important to note that they did not share surnames and rarely had the same home addresses as loved ones who were listed on sex offender registries, which may explain why they felt their stigmas were not immediately perceivable by others. Despite the fact that they understood their stigmas as invisible, however, this was an unpleasant reality for these participants. Support partners who dealt with perceived invisible stigmas struggled with whether or not to reveal their close associations to RSOs, worried about whether or not their stigmas were already known to other individuals, and brooded over 
the possibility that other individuals would not be accepting of their spoiled identities.

As Lauren, a 64-year-old mother of a RSO, observed:

Honestly, I do feel stigmatized. But, I don't think most people know about it. It's hidden. I walk among lots of people each and every day. Do they know I'm so close to a hated type of person? No. If they did, if they knew I was trying to help him, I fear some would then hate me.

\section{Passing}

Support partners who perceived having invisible stigmas utilized two distinct strategies to manage their spoiled identities. The most common of these stigma management techniques involved "passing" as someone who was not intimately associated with RSOs. In the work of Goffman (1963), an individual who engaged in passing hid "information about his real social identity, receiving and accepting treatment based on false suppositions concerning himself" (p. 42). A more contemporary definition described the phenomenon as a "cultural performance whereby one member of a defined social group masquerades as another" for purposes of experiencing the privileges given to individuals who are not stigmatized (Leary, 2012, p. 31). Taking these interpretations together, the strategy of passing contained herein may be thought of as actively choosing not to disclose invisible stigma, so as to appear to be a member of a nonstigmatized group, in order to avoid being dealt with in undesirable ways and thereby gain social acceptance.

A wide variety of stigmatized social groups used and continue to use the method of passing to manage their stigmas. Passing to dodge stigmatization was likely first utilized in America by light-skinned Blacks and Latinos who posed as Whites in order to avoid the harsh treatment that awaited darker-skinned Blacks and Latinos (Larsen, 1929). Lesbian, gay, bisexual, and transgender individuals often participate in passing. These 
individuals have constructed false heterosexual identities (Woods, 1994) with the objective of avoiding hostility and prejudice from others. Passing to escape stigmatization is also apparent in the lives of individuals who have health-related conditions. Individuals with HIV/AIDS may keep their statuses under the radar and largely hide their associated complications (Siegel, Lune, \& Meyer, 1998; Tewksbury \& McGaughey, 1997). Individuals with mental illness are often labeled as incompetent and dangerous, without regard to their abilities to function in society. As a result, these individuals may not openly advertise their statuses (Pescosolido, 2013). Ex-offenders, too, may guard their criminal histories from others, for fear of discrimination and rejection (Jones, 2003). In the same way, support partners of RSOs occasionally presented themselves as individuals who were not intimately associated with RSOs, in order to escape discrimination and maintain social acceptance.

The aforementioned stigmatized groups usually do not see their stigmas as discernible, like some support partners of RSOs in this study. Thus, consistent with Goffman's prediction (1963), these participants' principal strategy for coping with their stigmas was acting as persons who were not stigmatized - those who were not intimately associated with RSOs. "I intentionally do not reveal my relationship with my son," confirmed Hope, whose son was convicted of indecent liberties with a child, "because I don't want anybody to know what he is and what I am." Similarly, Traci disclosed, "Not a lot of people know that I'm supporting Nelson."

Among these participants, passing involved concealment. In other words, some support partners took preventative measures to keep other individuals from learning too much about them, because such information may have revealed their disgraced standings. 
This phenomenon was most prevalent among ex-spouses of RSOs, who often went to great lengths to camouflage their formal relationships with RSOs. This was deemed the most suitable approach by these women, because limited information meant there would be fewer opportunities for their stigmas to negatively influence their children. These women believed that their children would be more likely to avoid social rejection and grow up as "normal" kids, if knowledge of their connection to their former partners was limited. One month before her husband was to plead guilty to one count of first-degree sexual abuse for allegedly assaulting a 12-year-old girl, Amelia decided to end their marriage of 8 years:

It's what had to be done. I'm still his support person, but I had to get the divorce, so that the kids and I could escape the stigma. I didn't want to. I still love him, but it's for the best. Their father is so stigmatized, but so am I, just secretly. I don't want this to reach my kids, so I couldn't have him living with us. I couldn't have any marital link to him.

The 45-year-old mother of two proactively separated from her husband, in order to protect her own discredited status and those of her children from becoming public:

I don't want school knowing. If they know I'm supporting him, they might try to take the kids away. I don't want people knowing that he's got the same address as us. He had to move out, too. By keeping a distance, people don't know that me and my kids are followed by the shadow that haunts my ex-husband every single day.

In much the same way, Gloria, whose ex-husband was convicted of statutory rape, described how she was no longer romantically involved with him, sparing her children from the public stigmatization:

We interact for his treatment and so he can see the kids. But, besides that, we both decided that I needed to remove myself from the situation, so that the kids and I wouldn't suffer from the criticism and harassment that he gets. Also, so the connection between us is not broadcast as much, for me and the kids. 
Former spouses desperately wanted to protect themselves and their children from discrimination and social rejection that they believed would transpire, if their stigmas were exposed or became immediately perceivable by others. In attempting to do so, they concealed their connections to RSOs through divorces and the establishment of separate residences; however, such a strategy likely compromised their roles as support partners. Hiding the support-partner-sex-offender relationship meant limited communication and time spent with RSOs, and this made it difficult for them to adequately support them. In addition, support partners who attempted to pass could not be called upon by RSOs at all times. This presumably makes RSOs feel isolated at times, if not all the time, and may cause them to question if they are able to count on their support partners during crises. When RSOs cannot depend on their support partners, they may turn to less prosocial avenues to survive, including criminal activities.

\section{Covering}

Apart from concealing their relationships with RSOs and passing as nonstigmatized individuals, a few of these support partners utilized fabrication, or “covering” to use Goffman's (1963) term, in order to manage their stigmas. Telling deceptive stories or outright lies were common forms of covering used by these participants for the purposes of hiding their formal relationships with RSOs. "When I have to take Bill to his treatment sessions," stated Lynn, whose husband was convicted of second-degree sodomy, "I sometimes make up excuses about where I'm going." She did not want individuals outside of her immediate family knowing about her intimate association to a RSO: 
It's not right that I have to do this, but I tell coworkers that I'm taking time off to visit friends. I tell friends that I can't visit, because I'm working. In reality, I'm taking my husband to group or paying his fines at the probation office or taking him to the probation officer. I don't want to keep reminding people that he's a sex offender or that I'm a bad person for helping him.

By blatantly misrepresenting their activities or social identities, these participants created false knowledge to replace truths that would reveal their close link with RSOs. Edmund, whose son was convicted of possessing child pornography, recalled:

I have told strangers that I have no children, so that I distance myself from the drama that my son faces. I know I'm labeled if I come out, so I don't talk to a lot of people. When I do, I try to keep it strictly about business. No need to get personal or reveal something like that about myself.

As was the case for these support partners, Edmund was guarded with respect to his status as a confidant of a registered sex offender and created an alternative persona, or fictional "cover story," where he was childless, in order to deflect others from the discovering his stigma.

\section{Summary}

Despite the fact that numerous supporter partners saw themselves as recipients of visible courtesy stigmas, some participants felt that they carried with them marks of disgrace that were hidden or not readily apparent to others. It is important to note, however, that these individuals may have unknowingly belonged to the discredited, rather than the discreditable, as sex offender registries presumably linked them to RSOs. And yet, unlike those who perceived having visible stigmas, they did not share surnames and rarely had the same home addresses as loved ones who were listed on sex offender registries, potentially making them discreditable - persons with stigmas that were unknown but possibly discoverable. It was recently asserted that RSOs shared features of 
the discredited and the discreditable (Evans \& Cubellis, 2014), and this seems to be the case with their support partners, who commonly face and manage courtesy stigmatization.

As Goffman (1963) predicted, support partners who perceived having invisible stigmas found themselves in uncomfortable positions, forced to ruminate on whether "to display or not to display; to tell or not to tell; to let on or not to let on; to lie or not to lie" (p. 42). They ultimately attempted to pass as individuals who were not intimately associated with RSOs and used covering to deflect other individuals from the discovering their stigmas. Passing always involved concealment, whereby preventative measures were undertaken by participants to keep other individuals from learning personal details about them, in order to prevent their stigmas from receiving attention. This strategy was most widespread among ex-spouses of RSOs, who believed such a technique would best protect themselves and their children. This was considered to be the most suitable approach by these women, because limited information meant there would be fewer opportunities for their stigmas to negatively influence their children. These women believed that their children would be more likely to avoid social rejection and grow up as "normal" kids, if knowledge of their connection to their former partners was limited. Covering, or the use of fabrication, was a less common way that support partners attempted to manage their stigmas. With this tactic, lies were devised to generate false knowledge, and these misrepresentations were ultimately used to replace truths, which would otherwise expose their statuses as support partners of RSOs. Given the influential nature of sex offender registration on participants who saw themselves as representatives of the discredited, the next chapter considers support partners' perceptions of SORN. 


\section{CHAPTER VII}

\section{PERCEPTIONS OF SORN}

In Chapter V, the fact that that many support partners saw themselves as stigmatized individuals because they accepted RSOs and offered them help was uncovered. Chapter VI subsequently showed how these participants attempted to manage such courtesy stigmas. In doing so, it revealed that a majority of support partners believed that their discredited social standings were readily apparent to other individuals, and these participants attributed this reality to their loved ones' statuses as RSOs. In other words, SORN was blamed for having their stigmas exposed to society at large. Given the allegedly influential nature of SORN policies on perceived stigmatization, this chapter further explores support partners' perceptions of such laws. As a group of individuals who are intimately associated with RSOs, they presumably have unique experiences with and impressions about SORN that may assist with further understanding the utility of such legislation.

Analysis of interview data revealed that there were three primary areas of perceptions that support partners had concerning SORN policies, all of which suggested that such laws were ineffective strategies for addressing sex offenses. First, participants believed that SORN was incapable of adequately raising public awareness about sex offenders in communities. Second, support partners felt that this type of legislation was unable to impact sex offender recidivism. And, third, participants saw SORN as inappropriate for most sex offenders, including their loved ones. 


\section{Incapable of Adequately Raising Public Awareness}

Most support partners in this study described SORN as an ineffective approach to the management of sex offenders. A common perception across participants was that such policies did not adequately raise public awareness of the presence of sex offenders in communities. Specifically, these support partners believed that placing sex offenders on publicly available, online registries was an imperfect attempt at making the identities and whereabouts of such lawbreakers known. "When I look at the websites, it's not all there," contended Rupert, “and it's flawed, because I can't see everybody that's dangerous." Like many other participants, Rupert correctly pointed out that sex offender registries were not comprehensive lists of sex offenders. Many perpetrators of sex offenses are neither detected nor successfully prosecuted, some may avoid SORN through plea agreements or because their specific criminal offenses do not obligate them to register, and others may fail to adhere to SORN requirements. As Nicole explained:

It's crazy to have registries. They make people think that all offenders who offend sexually and attack kids are on there. That's not true. A lot of victims don't come forward, and if they do, they can't always get a conviction. My husband said a guy he met in jail was accused of violently raping his granddaughter, but he ended up getting a plea deal, and the guy didn't have to register or anything.

These support partners accurately understood that not all individuals who engaged in sex offenses were listed on registries, and they used this notion to defend their impressions that SORN did not satisfactorily inform the public about the identities and locations of sex offenders and thus was futile.

And yet, some participants expressed that the use of SORN to inform the public about sex offenders was ineffective for another reason. These support partners believed 
that publicly available sex offender registries provided society with information about convicted sex offenders that was not always accurate and often misleading. Candy talked about the fact that her neighbor three houses down was a RSO, but the information listed on his registry page was incorrect:

I followed Greg's case pretty closely. He pled guilty to first-degree rape, the one he was originally charged with. But the registry says he was convicted of thirddegree rape, which is a big difference. First-degree rape means force was used, and third degree is more like an age difference thing that was not with force.

For these participants, information about convicted sex offenders, which was revealed to them through SORN, was not in accordance with fact or left room for interpretation, which caused them to believe that these laws could not accurately advise the public regarding registrants' respective threats to safety. As Erin explained:

For me, if a guy has a big age difference between the victim, and if the victim was a child, that's a serious thing and that person is a threat to my family. If they are closer in age to the victim, and the victim was older, I don't feel the person is as bad. So, how can I use online lists of sex offenders, if they don't even update the age of the victim? My husband's victim was 14, and he was 20. That was five years ago. The registry shows that he's 25 now, but it still says she is 14 . As the years go by, he's going to be 30 and 40 , but she will still be 14 on there.

Erin felt that as time passed, her husband would only appear to be more of a threat, because the age difference between him and his victim would increase. Information regarding the victim was perceived as misleading, and like other support partners, this perceived inaccuracy made her unable to trust what was conveyed through SORN, particularly with respect to whether or not registrants were serious offenders who posed a risk to society.

The attitude that SORN policies may produce inaccurate or misleading data is congruent with prior work, where publicly available registries were found to have 
contained erroneous and deceptive information due to errors, incomplete data, outdated records, and other mishaps (Salmon, 2010). For instance, Tewksbury (2002) found that $43 \%$ of sex offender profiles on the Kentucky Sex Offender Registry were missing a photograph. Levenson and Cotter (2005a) reported that more than one-half of their sample of 183 RSOs had profiles on the Florida Sexual Offenders and Predators Registry that listed misinformation. According to these support partners, invalid and incomplete information on sex offender registries made determining convicted sex offenders' risk levels extremely difficult, if not impossible. As a result, SORN was viewed as inadequate for the purposes of increasing knowledge about sex offenders to maximize public safety.

\section{Unable to Impact Sex Offender Recidivism}

Apart from believing that SORN did not effectively raise public awareness about sex offenders in communities, support partners often saw such laws as unable to influence recidivism. In particular, these participants felt that future sex crimes committed by already-convicted sex offenders could not be prevented through SORN policies. Patty reflected on the efficacy of having personal information about her husband and other convicted sex offenders listed on registries:

I think that it doesn't make anybody any safer. That's for sure. I mean, putting my husband on the list doesn't mean his chances of going back [to crime] are any less. Take any sex offender, for example, it doesn't make a difference if they're posted online or not. Being on there is not making a difference as to whether or not they're going to do it again. A person on it is the same as a person off of it.

As was the case for Patty, these support partners believed that whether or not previously convicted sex offenders were placed on publicly available, online registries had no 
influence on their future behaviors. "It shouldn't matter if they're on a list or not," Lynn speculated, "it's not changing anything."

The most common explanation behind this perception was an attitude that sex offenders, on the whole, did not frequently reoffend. Taylor posed a rhetorical question, asking, "If sex offenders don't recidivate a lot anyway, why the hell put them online like that?" Inherent in SORN legislation is the notion that sex offenders are very likely to reoffend, and this assumption was questioned by numerous support partners. Ruby, who was working toward a criminal justice degree, shared a representative sentiment:

They're all like, "Put them on a registry." But, the problem is, sex offenders aren't the people we should be worried about. There are all kinds of other offenders who repeat their crimes, and sex offenders usually don't. So why are we so invested with punishing sex offenders with registries?

Interestingly, all support partners with a four-year college degree or higher felt that sex offenders were among the least likely criminals to recidivate and used this notion as a reason to describe SORN as an ineffective approach to the management of sex offenders in communities. This finding was consistent with the views of parole board members (Tewksbury \& Mustaine, 2012) and community corrections professionals (Payne, Tewksbury, \& Mustaine, 2013) reported in earlier research, where criminal justice officials with more education were less likely to believe in the efficacy of SORN policies. At the same time, in a larger and more recent study (Mustaine, Tewksbury, Connor, \& Payne, 2015), which compared and contrasted the perceptions of law enforcement officers, prosecutors, prison wardens, parole board members, and community corrections professionals, it was found that criminal justice officials who believed SORN laws to be ineffective had the most formal education. It appears, then, that education is a common determinant of attitudes and beliefs about the utility of 
SORN, with more educational attainment yielding less favorable assessments. As Wallace, who held a Ph.D. in computer science, insisted:

Burglars, robbers, killers, and thieves - I'm more concerned about them doing it again. Sex offenders are not going to do it again, and these other people are definitely more likely to. If there's going to be registries, let's do them for the criminals who keep on doing crimes.

Participants with more education may have been exposed to and therefore more knowledgeable about empirical evidence regarding sex offenders. This research largely suggests that sex offenders, on the whole, have relatively low rates of recidivism (Furby et al., 1989; Sample \& Bray, 2006), especially in comparison to other criminal offenders (Langan \& Levin, 2002; Sample \& Bray, 2003), and particularly when treated (Hall, 1995; Hanson et al., 2002; Losel \& Schmucker, 2005).

A few support partners, however, failed to mention the typically low recidivism rates of convicted sex offenders. Instead, in order to explain SORN's inability to stop future sex crimes, they asserted that public identification and exposure of previous sex offenses through such laws did not deter RSOs. In other words, publicly revealing the identities and whereabouts of sex offenders was seen as no better than concealing such information, because, in their eyes, sex offenders who wanted to sexually offend again would not be discouraged and "find a way" to continue their illegal activities. As Sheryl explained:

Regardless if they're on a list and people know who they are and where they live, some of them are still going to do what they're going to do. If they got a drive to do something, they're going to go through with it.

Although not an extremely prevalent view, this perspective is interesting, because it directly challenges one of the fundamental rationales behind SORN legislation - 
specific deterrence. It is also congruent with prior research (Tewksbury \& Lees, 2007), where a majority of RSOs expressed that being registered would not prevent them from reoffending if they so desired. An expressed goal of SORN is to restrict the possibilities that already-convicted sex offenders have for participating in criminal sexual behavior again by "outing" them to the public and making them feel vulnerable to detection. And yet, some participants dismissed this logic, believing that public labeling did not discourage sex offenses among previously convicted sex offenders.

\section{Inappropriate for Most Sex Offenders}

Beyond seeing SORN policies as failing approaches that did not adequately raise public awareness about sex offenders and could not substantially minimize sex offenders' likelihood of reoffending, support partners often thought of these laws as ineffective because they were supposedly inappropriate for most sex offenders, including their loved ones. That is, they believed that SORN was only suitable for certain types of sexual perpetrators, and by putting other, less serious sex offenders (i.e., their loved ones) on registries, determining who was and was not dangerous became impossible. "Not everybody should be put on registries," announced Max, "because not everybody needs to be on there." He continued, "If we leave everybody on there, how can you or I tell who is a risk?" This view corresponded with the narratives of RSOs in a prior study (Tewksbury \& Lees, 2007), where registrants felt that it was important to be able to differentiate between "true sex offenders" who are "actually dangerous" and themselves, if registries were to be effective (p. 394).

The most potent image of sex offenders who were deemed worthy of public identification was that of the repeat sexual lawbreaker. These sex offenders were 
described as individuals who committed sex offenses after already having been convicted of such crimes in the past. These types of sex offenders were viewed by many participants as unredeemable and therefore acceptable targets of SORN. Tabitha offered her perspective:

Look, if somebody did something one time, it never happened before, we should give them a break. I mean, they should be given the chance to rehabilitate themselves, attend treatment, and go through less punishment. Let's keep the registry and telling everybody what they did for those who do something a second time. If you did it once, ok, but if you did it twice, you did it again. It means you are actually a problem.

As Tabitha's words suggested, these participants perceived sexual recidivists as unable to recover from their transgressions, because subsequent sex crimes were signs that such individuals were true risks to public safety. In turn, as actual threats to society, these sex offenders were seen as deserving public exposure through SORN. In this way, SORN was considered to be a form of punishment or a mechanism that was inflicted on individuals as vengeance. Such retribution was perceived as appropriate for sex offenders who offended sexually again. It should be noted, however, that all support partners were supporting loved ones who were first-time sex offenders, and described images of the repeat sexual lawbreaker were thus inconsistent with those of their loved ones.

At the same time, it was not unusual for support partners to consider sex offenders with "real" victims as appropriately subjected to SORN. Specifically, sexual lawbreakers who targeted individuals less than 18 years of age, or "real" victims, were often viewed as despicable individuals who deserved such punishment, because children were seen as quintessential victims - helpless, innocent, and weak. "People need to know who the 
people are who mess with children," declared Susan. As perpetrators against an authentic category of victims, or individuals who were generally agreed upon to be "unable to protect themselves" and "exploitable," child sex offenders were discerned as a justifiable group of criminals for the purposes of public exposure. As Edmund explained:

Guys who actually fool with kids are monsters, ok? I'm not a supporter of that. It's not really a good thing to put people on those lists, but sometimes you have to do what you have to do. If a person attacked a child, that's one thing. You have to lay down the law on them, I think. They're nasty. What they did was nasty. Let's deal with them. Let's put them up online, and let's let people know who they are, ok?

Participants who served as support partners for RSOs who were convicted of possessing child pornography were the most willing to approve of publicly labeling child sex offenders. At first, this may appear to be a contradiction, because none of them believed that their loved ones should be made to register as sex offenders, in spite of viewing images and videos of children participating in sexual activities. However, Gus explained the logic:

My wife's brother, he didn't touch any children. He didn't assault young kids or anything like that. It's ridiculous for him to be on there, the registry and everything. People who actually touch kids, who actually violate them, who actually do actual stuff to kids are the ones that need to be on the registry. I want to know about them.

The narratives of Gus and other support partners who supported RSOs with child pornography convictions introduced the concepts of "real" victimization and "real" sex offenders, which were distinct from "real" victims. Like Gus and other participants, a child pornography offense was considered to be a "victimless" crime, whereby victimization was not "really" happening (i.e., not "real" victimization), and thus inappropriate for SORN designation. From the perspective of Gus, his brother-in-law did 
not physically assault or have contact with a child, so his loved one was not involved in "real" victimization as a "real" sex offender.

To elaborate, when establishing that only the "most serious" or "real" sex offenders should be listed on registries, support partners who supported family members who were convicted of possessing child pornography made deliberate distinctions between their loved ones who "only watched" children - not "real" victimization - and sex offenders who had physical contact with children - "real" victimization, presumably to maintain a stance against having their loved ones registered. When children were not physically touched, they were not seen as "real" victims to those supporting sex offenders with child pornography offenses. As with participants who felt that recidivists should be obligated to register as sex offenders, these support partners described images of appropriately-RSOs that did not match depictions of their loved ones.

\section{Summary}

Most support partners believed that SORN was an ineffective tool for public safety. These participants often expressed that placing sex offenders on publicly available, online registries was flawed, as registries were not comprehensive lists of sex offenders. They used this idea to point out that SORN did not effectively inform the public about all sex offenders and was therefore futile. Moreover, some participants expressed that the use of SORN to inform the public about sex offenders was not effective, as it often provided society with information about convicted sex offenders that was inaccurate and misleading, making such an approach unable to accurately advise them and others regarding registrants' actual threats to public safety. 
At the same time, support partners commonly felt that SORN policies were unable to stop future sex crimes by previously convicted sex offenders, for two reasons. First, sex offenders were often collectively viewed as unlikely to reoffend, regardless of their public exposure through SORN. In fact, all participants with a four-year college degree or higher felt that sex offenders were among the least likely criminals to recidivate and used this notion as a reason to describe SORN as an ineffective approach. Second, a minority of participants explained their pessimistic perspectives on SORN by asserting that being registered was not a deterrent to subsequent sex crimes. Simply put, sex offenders who wanted to sexually offend again, in their eyes, would find a way to continue their illegal activities, if so desired, regardless of registration status.

Further, support partners often thought of SORN as ineffective because they were supposedly inappropriate for most sex offenders, including their loved ones. That is, they believed that this type of legislation was only suitable for certain types of sexual perpetrators, and by putting other, less serious sex offenders (i.e., their loved ones) on registries, discerning the dangerousness of registrants was not possible. The most pervasive image of sex offenders who were deemed worthy of public identification, which was described as a form of punishment, was that of the repeat sexual lawbreaker. These types of sex offenders were viewed by many participants as unredeemable and risks to public safety, making them acceptable targets of SORN. Sex offenders with "real" victims, or children, were another group of criminals believed to be appropriately subjected to SORN, and their perceived wicked nature made them justifiable recipients of public exposure. Participants who served as support partners for RSOs who were convicted of possessing child pornography were the most eager to support publicly 
identifying child sex offenders, and they established that their loved ones should not be similarly exposed, because their loved ones were not "real" sex offenders and their offenses were allegedly not responsible for "real" victimization. When participants described images of the repeat sexual lawbreaker and the child sex offender, they made certain to portray their loved ones as entirely distinct from these "real" sex offenders, presumably to defend their positions that their loved ones should not be registered.

Chapter VIII discusses the findings of this chapter in more detail, as well as those of Chapters IV, V, and VI, in order to explain their contributions to knowledge. Limitations of this study and corresponding policy implications are also presented. 


\section{CHAPTER VIII}

\section{DISCUSSION}

The present study provided in-depth information and extensive details about the lived experiences, identities, and perceptions of individuals who served as formal support partners for their loved ones - RSOs who were undergoing sex offender treatment while on community supervision. Specifically, using participant narratives, this research qualitatively examined their motivations for serving as support partners, costs associated with such roles, stigma management techniques, and attitudes and beliefs toward SORN. This final chapter places these findings in a larger context to explain this study's overall contributions to knowledge and suggests corresponding policy implications. It also presents the limitations of this work.

\section{Contributions to Knowledge and Policy Implications}

This investigation advanced the current state of knowledge on a variety of fronts. When support partners' motivations for providing support were explored in Chapter IV, several themes emerged, which echoed earlier research regarding RSOs and mentors in the criminal justice system. Among participants, the most frequently expressed reason for initially forging formal relationships with RSOs was a feeling that no one else was willing to do so. This is consistent with Tewksbury and Connor's (2012b) work, where RSOs anticipated having decreased social networks following release from prisons, because of their public labeling. At the same time, it is congruent with prior studies that showed that RSOs were likely to lose relationships (Tewksbury \& Lees, 2006a; 
Tewksbury, 2004, 2005) and endure social stigmatization (Evans \& Cubellis, 2014; Robbers, 2009; Tewksbury, 2005, 2012; Tewksbury \& Lees, 2006a, 2007; Uggen et al., 2004; Zevitz \& Farkas, 2000a) as a result of their statuses. In this way, the present study confirms that RSOs are a category of ex-offenders especially in need of social support. This suggests that specifically designating individuals to serve formal roles as support partners is worthwhile, as it helps to guarantee that RSOs have at least one prosocial contact in communities where they may face intensified hardships as a result of their public identification. Future research should examine the narratives of RSOs to understand if, in fact, support partners are useful for facilitating successful reintegration. While the influence of their material and social support should be considered, their ability to discourage RSOs from continued criminal activities should also be assessed.

Numerous participants were also motivated by a fear that society's harmful treatment of RSOs would more strongly impact their loved ones if they did not become their support partners. This indicates that the collateral consequences of SORN were not only perceived and experienced by registrants (Burchfield \& Mingus, 2008; Levenson \& Cotter, 2005; Levenson et al., 2007; Robbers, 2009; Tewksbury, 2005, 2012; Tewksbury \& Connor, 2014; Tewksbury \& Lees, 2006a, 2006b; Zevitz \& Farkas, 2000a), but they were also acknowledged as likely threats by others presumably closest to them. As a result, SORN's negative impacts on convicted sex offenders were recognized by a potentially more reputable source to such a degree that it influenced their decision making. In particular, employment and housing were two areas of concern expressed by participants with respect to their loved ones, which reinforces the aforementioned literature on collateral consequences, and which almost always reveals that SORN makes 
permanent places to live and stable jobs unrealistic for a majority of RSOs. Therefore, support partners may be important social agents for RSOs, as they may help such offenders obtain employment and housing accommodations that are otherwise out of the question. What is more, it is now known that SORN not only impacts the lives of RSOs and their family members, but also impacts those of their treatment support partners.

Further, a belief that RSOs had redeemable qualities, such as intelligence and inherent goodness, was the driving force behind many participants' decisions to be support partners at the outset. This parallels other work, where mentors who worked closely with ex-offenders held positive views of inmates and ex-offenders (Denney \& Tewksbury, 2013; Kerley, Bartowski, Matthews, \& Emond, 2010). This suggests that society at large should be made aware of the desirable characteristics of RSOs and other stigmatized groups as a means to breaking down stereotypes and subsequently increasing the likelihood of acceptance and support. With respect to RSOs, education campaigns and other ways to spread the word should emphasize the fact that these offenders, on the whole, have relatively low rates of recidivism (Furby et al., 1989; Sample \& Bray, 2006), especially in comparison to other criminal offenders (Langan \& Levin, 2002; Sample \& Bray, 2003). Drawing specific attention to the likely impact of sex offender treatment reducing recidivism among RSOs (Hall, 1995; Hanson et al., 2002; Losel \& Schmucker, 2005) - may also prove to be advantageous. In this way, RSOs may become more humanized, or at least viewed as less of a threat, increasing the prospect of family members and other individuals affording them opportunities for successful reintegration. And yet, such efforts may be unlikely and these results may be difficult to achieve, given the stigmatization of RSOs and those closest to them. 
In addition, a majority of support partners explained why they decided to continue their formal relationships with RSOs. As formal associations evolved, participants chose to maintain such arrangements for internal reasons. In other words, support partners clearly got something out of the associations, too, which reinforced their commitment. This is not unexpected, as satisfaction was established in prior research (Vecina, Chacon, Sueiro, \& Barron, 2010) as a primary way to explain why individuals who volunteered their time continued to do so. Specifically, one perceived reward was the ability to become closer to RSOs, which is akin to the narratives of other mentors of ex-offenders, who believed that satisfying personal relationships with halfway house residents that developed over time were the greatest personal benefits of their roles (Denney \& Tewksbury, 2013). Preservation of formal relationships with RSOs also gave participants a sense of worth. This again corresponds to the experiences of other mentors of exoffenders, who reported that involvement with halfway house residents increased their self-esteem (Denney \& Tewksbury, 2013). Because support partners stayed in formal relationships with RSOs as a result of perceived personal benefits, community correctional officials and treatment providers should consider ways to reward current support partners for their efforts. This may be done through official acknowledgement of their endeavors and routine communications regarding their impacts on RSOs' progress. Such may serve as a means to encourage the maintenance of the support-partner-sexoffender relationship.

Chapter V assessed the costs that support partners encountered while formally supporting RSOs. Loss and deterioration of relationships were near-universal problems identified by support partners, as they attempted to help RSOs reintegrate into society and 
become law-abiding citizens. This is consistent with the experiences of many family members of RSOs who were not necessarily formally supporting them (Levenson \& Tewksbury, 2009; Tewksbury \& Levenson, 2009). However, this study revealed new information relevant to these phenomena. Specifically, the most commonly terminated and diminished relationships were those with newer and less intimate individuals. Nonetheless, the "strongest" associations often were completely destroyed or faded, too. Isolation was another perceived cost of helping RSOs. This self-imposed seclusion included behaviors that RSOs (Burchfield \& Mingus, 2008; Levenson \& Cotter, 2005a; Levenson et al., 2007; Robbers, 2009; Tewksbury, 2005, 2012) and their family members (Farkas \& Miller, 2007; Tewksbury \& Levenson, 2009) reported in other studies, such as limiting public activities and structuring time to interact with fewer individuals. At the same time, in their attempts to isolate themselves, numerous support partners found their homes to be places where they could be sheltered from encounters with other individuals and fully let their guards down. This parallels the work of Tewksbury (2013), who found that RSOs listed on university sex offender registries similarly utilized the classroom as refuge, where their feelings of vulnerability were largely minimized and some level of comfort arose. It is important for community corrections officials and treatment providers to ensure that RSOs and their support partners have these "safety zones" or places where they can feel secure, escape stress, and engage in activities that are meaningful to them. This will help RSOs avoid backsliding into criminal behavior and reduce burnout among their support partners.

Further, harassment was identified by many support partners as a cost of helping RSOs. Although prior studies reported that threats and hostile actions were directed 
toward a substantial minority of family members of RSOs (Levenson \& Tewksbury, 2009; Tewksbury \& Levenson, 2009), this study shows that persistent torment was experienced by a majority of support partners. This made sense, as support partners presumably spent more time with RSOs in public than other family members, making them more susceptible to threats and intimidation. Participants who lived with RSOs were confronted with the most persistent torment. This matches the findings of Levenson and Tewksbury (2009), who found that those who lived with RSOs were more likely to experience threats and harassment by neighbors. Perhaps the most striking finding, however, was that criminal justice officials were viewed as the most common source of such harassment. Similarly, in Farkas and Miller's (2007) study, probation and parole officers were blamed for constantly bothering and invading the privacy of family members. Criminal justice officials, specifically probation and parole officials, should be trained to be sensitive toward clients and individuals who are supporting RSOs, so as to avoid derailing their client's well-being and support. When stopping by or searching homes and other locations where places of refuge or safety zones may be established, special care should be taken to avoid tainting the environment. By unnecessarily adding stress and ridicule to areas of life once thought to be exempt from such, criminal justice officials may be reducing RSOs' social support and subsequently increasing their likelihood of failing to successfully reintegrate.

Lastly, many support partners believed that they were stigmatized - described, labeled, and regarded in certain ways by other individuals to show strong disapproval because they served supporting roles for a group of highly defamed criminals. This supports Goffman's (1963) notion that there is a "tendency for stigma to spread from the 
stigmatized individual to his close connections" (p. 30). Indeed, because a support partner is necessarily "related through the social structure to a stigmatized individual," the RSO, society at large may "treat both individuals in some respects as one" (Goffman, 1963, p. 30). In the eyes of these support partners, this courtesy stigmatization was almost always the most powerful cost. Although family members of RSOs often reported experiencing social stigma (Farkas \& Miller, 2007; Levenson \& Tewksbury, 2009; Tewksbury \& Levenson, 2009), support partners may have endured stronger and more frequent stigmatization, which would explain their perceptions of such being so influential in their lives. As was the case with harassment, the fact that support partners are presumably closer to RSOs than other family members, because of their regular interactions with RSOs, may illustrate how courtesy stigmas are intensified for them. However, it may be more than mere closeness. Sigelman, Howell, Cornell, Cutright, and Dewey (1991) found that male college students who had voluntary, rather than involuntary, relationships with gay males were more likely to be stigmatized. Kulik, Bainbridge, and Cregan (2008) also showed that employees who freely associated with stigmatized coworkers were treated negatively. Thus, because support partners are close to and voluntarily forge relationships with RSOs, courtesy stigmas seem to easily attach to them, whereas such stigmas may not as strongly attach or attach at all to other relatives who have no decision to make regarding their familial linkage. Moreover, support partners who experienced stigma often reported that they were viewed differently than in the past, which is congruent with the perceptions of other recipients of courtesy stigmas, including family members of Alzheimer's patients (MacRae, 1999), relatives of 
individuals with mental illness (Corrigan \& Miller, 2004), and parents of children with disabilities (Green, 2004).

The costs of serving as support partners of RSOs were clearly numerous and widespread. Loss of personal relationships, weakening of associations, isolation, harassment, and stigmatization would be daunting challenges for anyone. However, support partners voluntarily accept their roles and devote time, energy, and other resources to RSOs, and their efforts are very likely to be met with these negative reactions from society, including criminal justice officials, family members, and friends. This suggests that support partners may need social support of their own, if they are to stay the course and continue to help RSOs with completing treatment and avoiding future offenses. Apart from motivating them through the aforementioned rewards, support partners should be offered and encouraged to participate in individual counseling sessions with treatment providers or other therapists. Also, sex offender treatment curriculums should allow support partners to meet and comingle with each other, in much the same way that RSOs meet and interact with each other in group-based sex offender treatment. In these ways, support partners may be afforded support and positive reinforcement that is noticeably absent from others in society who sever ties with, withdraw from relationships with, intimidate and torment, and discount them.

In Chapter VI, analysis focused on how support partners coped with their courtesy stigmas. More than one-half of support partners perceived themselves as carrying visible stigmas, and they attributed this reality to their loved ones' statuses as RSOs. That is, participants believed that their stigmas were revealed to society at large, because their loved ones were listed on publicly available, online sex offender registries. It is 
important to note that these support partners either shared a surname or home address with their loved ones, which likely explained why they felt that sex offender registries uncovered their stigmas. Thus, SORN not only has the potential to damage the reputation of RSOs (Evans \& Cubellis, 2014; Tewksbury, 2012) and their family members (Farkas \& Miller, 2007; Levenson \& Tewksbury, 2009; Tewksbury \& Levenson, 2009), but also has the ability to tarnish the character of individuals specifically devoted to helping RSOs reintegrate into society and become law-abiding citizens. With participants reporting that their stigmatization was responsible for (additional) numerous negative consequences, including destruction of relationships, weakening of associations, isolation, and harassment (see Chapter V), SORN as a generator of stigma directly and negatively impacts the welfare of support partners. Such legislation also forced support partners to actively manage their identities, increasing stress among yet another population. This adds to the collateral consequences of SORN and further calls into question the efficacy of such laws.

The most frequently used method for managing perceived visible stigmas was to publicly acknowledge such marks of disgrace. This parallels earlier work, where this strategy was used by other stigmatized populations, including individuals with direct stigmas, such as RSOs (Evans \& Cubellis, 2014), those with obesity (Hebl \& Kleck, 2002), and those with physical disabilities (Davis, 1961; Hebl \& Skorinko, 2005), as well as individuals with courtesy stigmas, such as parents of teenagers with ADHD (KoroLjungberg \& Bussing, 2009) and children of parents with Alzheimer's disease (Werner, Goldstein, \& Buchbinder, 2010). This technique allegedly relieved the tension otherwise experienced in interpersonal communication for two reasons. First, participants no 
longer had to hold off for other individuals to broach the difficult subject of their statuses. The finding that these participants felt defenseless against exposure and feared being "outed" before acknowledging their statuses is consistent with the experiences of RSOs reported in prior research (Burchfield \& Mingus, 2008; Levenson \& Cotter, 2005a; Levenson et al., 2007; Robbers, 2009; Tewksbury, 2004, 2005, 2012, 2013; Tewksbury \& Lees, 2006a, 2006b; Tewksbury \& Mustaine, 2009), where persistent feelings of vulnerability were among the most common problems facing registrants. It appears that RSOs and their support partners share apprehensions regarding disclosure of statuses.

Second, this strategy made support partners feel that they were effectively presenting themselves as candid and trustworthy, which counteracted their stigmas. Openness was said to balance the negative effects of stigmatization, and this is consistent with earlier studies on stigma management, where open recognition of visible stigmas improved public perceptions of the discredited (Davis, 1961; Hebl \& Kleck, 2002; Hebl \& Skorinko, 2005; Singletary \& Hebl, 2009). A recent qualitative study (Evans \& Cubellis, 2014), where RSOs commonly perceived honesty about their statuses to be an effective tool for achieving credibility in social encounters, was also congruent with the idea of acknowledgement being beneficial to stigmatized individuals.

Other participants intentionally distinguished their loved ones from stereotypical conceptions of RSOs, by describing loved ones' personalities and crime stories in a more tolerable light, so as to offer additional information that allowed for more favorable judgments. Specifically, support partners attempted to distance RSOs from images of violent predators who intentionally targeted children, because this was believed to increase their loved ones' opportunities for public acceptance and subsequently shape 
community perceptions of their support as justifiable. Interestingly, such approaches are reminiscent of the behaviors of RSOs found in Tewksbury and Lees' (2007) research, where nearly all of the 22 registrants distinguished themselves from those whom they saw as "real criminals," "dangerous," and "sexual predators" (p. 395). In establishing the difference between their loved ones and these sex offenders, they sometimes engaged in compensating, whereby they emphasized their loved ones' other desirable qualities in the process, to make up for their loved ones' transgressions. The tactic of differentiation was especially common among spouses, who overwhelmingly felt they had a vested interest in identity management, as they saw themselves as more intimately connected to RSOs through marriage. This assertion is supported by earlier research (Corrigan \& Miller, 2004), where courtesy stigmatization was found to be stronger for individuals who cohabitated with stigmatized persons than for those who did not. Spouses believed that other individuals, particularly other women with children, would be more likely to understand their support of their husbands and accept them once they understood that children were not directly assaulted. This reflects perceptions of the public, who largely viewed pedophiles, compared to other sex offenders, in the most negative light (Kernsmith et al., 2009).

Despite the fact that numerous supporter partners saw themselves as recipients of visible courtesy stigmas, some participants felt that they carried with them marks of disgrace that were hidden or not readily apparent to others. It is important to note, however, that these individuals may have unknowingly belonged to the discredited, rather than the discreditable, as sex offender registries presumably linked them to RSOs. And yet, unlike those who perceived having visible stigmas, they did not share surnames and 
rarely had the same home addresses as loved ones who were listed on sex offender registries, potentially making them discreditable. It was recently asserted that RSOs shared features of the discredited and the discreditable (Evans \& Cubellis, 2014), and this seems to be the case with their support partners, who commonly face and manage courtesy stigmatization.

As Goffman (1963) predicted, support partners who perceived having invisible stigmas found themselves in uncomfortable positions, forced to ruminate on whether "to display or not to display; to tell or not to tell; to let on or not to let on; to lie or not to lie" (p. 42). They ultimately attempted to pass as individuals who were not intimately associated with RSOs and used covering to deflect other individuals from the discovering their stigmas. Passing always involved concealment, whereby preventative measures were undertaken by participants to keep other individuals from learning personal details about them, in order to prevent their stigmas from receiving attention. This strategy was most widespread among ex-spouses of RSOs, who believed such a technique would best protect themselves and their children. This was considered to be the most suitable approach by these women, because limited information meant there would be fewer opportunities for their stigmas to negatively influence their children. These women believed that their children would be more likely to avoid social rejection and grow up as "normal" kids, if knowledge of their connection to their former partners was limited. Covering, or the use of fabrication, was a less common way that support partners attempted to manage their stigmas. With this tactic, lies were devised to generate false knowledge, and these misrepresentations were ultimately used to replace truths, which would otherwise expose their statuses as support partners of RSOs. 
Passing (Jones, 2003; Pescosolido, 2013; Siegel et al., 1998; Tewksbury \& McGaughey, 1997; Woods, 1994) and covering (Nack, 2008; Roschelle \& Kaufman, 2004; Siegel et al., 1998) strategies have been adopted and used by a wide variety of stigmatized individuals. However, hiding the support-partner-sex-offender relationship through these techniques likely compromises the roles that support partners play in the lives of RSOs. In order to conceal their relationships with RSOs, support partners had to limit their communication and time spent with loved ones, and this likely makes it difficult for them to adequately support them. In addition, support partners who attempted to hide their associations could not be called upon by their loved ones at all times. This presumably makes RSOs feel isolated at times, if not all the time, and may cause them to question if they are able to count on their support partners during crises. When RSOs cannot depend on their support partners, they may turn to less prosocial avenues to survive, including criminal activities. What is more, passing and covering might also perpetuate their stigmatization and that of RSOs, as their identities and associations to RSOs are hidden, ignored, and not confirmed. For these reasons, treatment providers and other mental health professionals should consider advising against these coping mechanisms, especially given that their stigmas may actually be visible through SORN. Future research should continue to examine stigmas management among RSOs and individuals who regularly interact with them as a means to finding the most effective approaches for well-being.

Chapter VII looked at the attitudes and beliefs of support partners toward SORN. Most support partners believed that SORN was an ineffective tool for public safety. These participants often expressed that placing sex offenders on publicly available, online 
registries was flawed, as registries were not comprehensive lists of sex offenders. They used this idea to point out that SORN did not effectively inform the public about all sex offenders and was therefore futile. This is a valid criticism of SORN, as many perpetrators of sex offenses are neither detected nor successfully prosecuted, some may avoid SORN through plea agreements or because their specific criminal offenses do not obligate them to register, and others may fail to adhere to SORN requirements.

Moreover, some participants expressed that the use of SORN to inform the public about sex offenders was not effective, as it often provided society with information about convicted sex offenders that was inaccurate and misleading, making such an approach unable to accurately advise them and others regarding registrants' actual threats to public safety. The attitude that SORN policies may produce inaccurate or misleading data is congruent with prior work, where publicly available registries were found to have contained erroneous and deceptive information due to errors, incomplete data, outdated records, and other mishaps (Salmon, 2010). For instance, Tewksbury (2002) found that $43 \%$ of sex offender profiles on the Kentucky Sex Offender Registry were missing a photograph. Levenson and Cotter (2005a) reported that more than one-half of their sample of 183 RSOs had profiles on the Florida Sexual Offenders and Predators Registry that listed misinformation.

At the same time, support partners commonly felt that SORN policies were unable to stop future sex crimes by previously convicted sex offenders, for two reasons. First, sex offenders were often collectively viewed as unlikely to reoffend, regardless of their public exposure through SORN. In fact, all participants with a four-year college degree or higher felt that sex offenders were among the least likely criminals to recidivate 
and used this notion as a reason to describe SORN as an ineffective approach. This finding is consistent with the views of parole board members (Tewksbury \& Mustaine, 2012) and community corrections professionals (Payne et al., 2013) reported in earlier research, where criminal justice officials with more education were less likely to believe in the efficacy of SORN policies. At the same time, in a larger and more recent study (Mustaine et al., 2015), which compared and contrasted the perceptions of law enforcement officers, prosecutors, prison wardens, parole board members, and community corrections professionals, it was found that criminal justice officials who believed SORN laws to be ineffective had the most formal education. It appears, then, that education is a common determinant of attitudes and beliefs about the utility of SORN, with more educational attainment yielding less favorable assessments. Participants with more education may have been exposed to, and therefore be more knowledgeable about, empirical evidence regarding sex offenders. Indeed, this research indicates that sex offenders, on the whole, have relatively low rates of recidivism (Furby et al., 1989; Sample \& Bray, 2006), especially in comparison to other criminal offenders (Langan \& Levin, 2002; Sample \& Bray, 2003) and particularly when treated (Hall, 1995; Hanson et al., 2002; Losel \& Schmucker, 2005).

Second, a minority of participants explained their pessimistic perspectives on SORN by asserting that being registered was not a deterrent to subsequent sex crimes. This perception is also supported by prior research. There is substantial evidence across numerous jurisdictions that SORN does not prevent convicted sex offenders from continuing to participate in sex offenses in the community (Agan, 2007). Whether or not sex offenders were subjected to SORN failed to predict which sex offenders would 
sexually recidivate in Arkansas (Maddan, 2008), Iowa (Adkins et al., 2000; Tewksbury \& Jennings, 2010), Massachusetts (Petrosino \& Petrosino, 1999), New Jersey (Tewksbury et al., 2012; Zgoba et al., 2008), and Washington (Schram \& Milloy, 1995). Similar results were found in New York, where Sandler and colleagues (2008) showed no support for the effectiveness of SORN in reducing sex offenses by previously convicted rapists, child molesters, or sexual recidivists. The lack of significant influence of SORN on recidivism remained, even when these rates were considered as a whole. The number of victims involved in sex offenses was also not reduced by SORN laws (Zgoba et al., 2008). Thus, based on these studies and the consistent claims of support partners, it becomes clear that SORN does not effectively deter convicted sex offenders from sexually reoffending. If anything, there is some evidence to the contrary. For example, in their analysis of National Incident-Based Reporting System data in 15 different states, Prescott and Rockoff (2011) found that SORN increased recidivism rates among sex offenders (see also Drake \& Aos, 2009; Letourneau, Levenson, Bandyopadhyay, Sinha, \& Armstrong, 2010). In short, it is fair to say that research across two decades and multiple U.S. jurisdictions indicates that SORN fails to improve public safety.

Support partners explained SORN's inability to influence sex offender recidivism by stating that sex offenders who wanted to sexually offend again would find a way to continue their illegal activities, if so desired, regardless of registration status. Although not an extremely prevalent view, this perspective is interesting, because it directly challenges one of the fundamental rationales behind SORN legislation - specific deterrence - from an experiential standpoint. It is also congruent with prior research (Tewksbury \& Lees, 2007), where a majority of RSOs expressed that being registered 
would not prevent them from reoffending if they so desired. An expressed goal of SORN is to restrict the possibilities that already-convicted sex offenders have for participating in criminal sexual behavior again by "outing” them to the public and making them feel vulnerable to detection. And yet, some participants dismissed this logic, correctly believing that public labeling did not often discourage sex offenses among previously convicted sex offenders.

Further, support partners often thought of SORN as ineffective because such was supposedly inappropriate for most sex offenders, including their loved ones. That is, they believed that this type of legislation was only suitable for certain types of sexual perpetrators, and by putting other, less serious sex offenders (i.e., their loved ones) on registries, discerning the dangerousness of registrants was not possible. This view corresponds with the narratives of RSOs in a prior study (Tewksbury \& Lees, 2007), where registrants felt that it was important to be able to differentiate between "true sex offenders" who are "actually dangerous" and themselves, if registries were to be effective (p. 394). The most pervasive image of sex offenders who were deemed worthy of public identification, which was described as a form of punishment, was that of the repeat sexual lawbreaker. These types of sex offenders were viewed by many participants as unredeemable and risks to public safety, making them acceptable targets of SORN. Sex offenders with "real" victims, or children, were another group of criminals believed to be appropriately subjected to SORN, and their perceived wicked nature made them justifiable recipients of public exposure. As mentioned, this parallels perceptions of the public, who reportedly feared child sex offenders more than any other type of sex offender (Kernsmith et al., 2009). Participants who served as support partners for RSOs 
who were convicted of possessing child pornography were the most eager to support publicly identifying child sex offenders, and they established that their loved ones should not be similarly exposed, because their loved ones were not "real" sex offenders and their offenses were allegedly not responsible for "real" victimization. When participants described images of the repeat sexual lawbreaker and the child sex offender, they made certain to portray their loved ones as entirely distinct from these "real" sex offenders, presumably to defend their positions that their loved ones should not be registered.

All of the criticisms of SORN pointed out by support partners are valid and suggest that such laws need to be reconsidered. Participants are correct in stating that SORN does not inform the public about all sex offenders. Without knowledge of all sex offenders, potential victims may not be able to effectively protect themselves. However, even if complete knowledge of all sex offenders was theoretically achievable, support partners are right in asserting that SORN may still be ineffective at guaranteeing public safety, because such often contains inaccurate or misleading information, due to errors, incomplete data, outdated records, or other mishaps. Such incomplete or invalid information makes the identification of convicted sex offenders and their whereabouts extremely difficult, if not impossible. At the same time, participants held accurate views of sex offenders as generally unlikely to reoffend, which may render SORN largely unnecessary. Further, there is substantial evidence across numerous jurisdictions that SORN does not prevent convicted sex offenders from continuing to participate in sex offenses, which supports the claims made by support partners about specific deterrence being impossible through such legislation. In addition, with more than 700,000 RSOs in the United States (National Center for Missing and Exploited Children, 2014), 
participants made a logical argument that SORN is overreaching and thus less useful for identifying sex offenders who are most likely to recidivate.

This denunciation of SORN is justified and signals the need for a more effective method of supervising convicted sex offenders in communities. SORN laws are focused on the control and surveillance of sex offenders, rather than their treatment (Zevitz \& Farkas, 2000b), despite the fact that sex offender treatment programs appear to be a promising means for managing sex offenders in the community. Treated sex offenders are consistently less likely to recidivate, in comparison to untreated sex offenders (Hall, 1995; Hanson et al., 2002; Losel \& Schmucker, 2005). As mentioned, this cannot be said of sex offenders who are and are not publicly identified through SORN, and in some cases, sex offenders who are publicly labeled are more likely to repeat sex offenses. More resources and attention by the criminal justice system should be afforded to treatment programs aimed specifically at convicted sex offenders and the roles that support partners play in helping such offenders desist from future crimes.

And yet, if SORN must remain the predominant approach to the management of convicted sex offenders, it may be wise to partially adopt the provisions suggested by support partners - obligating only some sex offenders to register and become publicly labeled. This would limit exposure and the myriad of drawbacks generally associated with publicly identifying sex offenders outlined in Chapter II and specifically related to support partners described in Chapter V and Chapter VI. Before being required to submit to SORN, however, convicted sex offenders should be individually assessed with respect to their propensities to sexually reoffend. Given SORN's negative ramifications for RSOs, their families, and support partners, every opportunity should be afforded to avoid 
public identification. If empirically validated assessments indicate that individuals are likely to pose a threat to society, they should be evaluated in the future at set intervals to determine their continued risk and whether or not SORN is necessary.

\section{Limitations}

The present study was not without limitations. The issue of generalizability was one concern. Although the number of participants was relatively small, the researcher was confident that the sample size was appropriate (see Chapter III). Specifically, no previously identified study had examined support partners of RSOs, so it was believed that 38 interviews were a good starting point for knowledge attainment and future inquiry. Also, given the exploratory nature of the investigation, the goal of the project was to interview enough participants to reach saturation (i.e., when no new themes or information arose from additional interviews). The researcher was convinced that thematic saturation was indeed achieved, after completing the interviews and examining the available data. The fact that saturation may have been reached with as few as 12 interviews (Guest et al., 2006) and a review of ethnographic research in leading criminology and criminal justice journals indicated that the median sample size was 35 for studies based on semi-structured interviews (Copes et al., 2011) supported the conclusion that the 38 completed interviews were satisfactory for the purposes of the present research. Nonetheless, findings may or may not extend to support partners who forge formal relationships with RSOs who are nonrelatives, adult females, or juveniles. At the same time, findings may or may not apply to support partners involved in other sex treatment programs operated by different treatment providers or living in regions outside of the South. Further, the sample was selected in a nonrandom fashion, and 
males, Nonwhites, and unmarried persons were underrepresented, which may have impacted the ability to extrapolate the findings.

\section{Conclusion}

In the end, the present study was the first known investigation to explore the lived experiences, identities, and perceptions of support partners of RSOs. Specifically, using participant narratives, this research qualitatively examined their motivations for serving as support partners, costs associated with such roles, stigma management techniques, and attitudes and beliefs toward SORN. This research offered support to previous studies in a wide variety of topical areas, including RSOs' experiences, family members of RSOs' experiences, mentors of ex-offenders' experiences, stigma and its management, and the utility of SORN, while also adding new insights to them. Chief among corresponding policy implications was the need to reconsider SORN as a strategy to address sex crimes, although additional suggestions were made regarding ways to increase and maintain formal social support of RSOs through the provision of rewards for support partners, restructuring of treatment curriculums to better assist support partners with their roles, and recommendation of best stigma management approaches. Ultimately, future inquiries should continue to examine support partners of RSOs, as a greater understanding of this population may expose the value of the support-partner-sexoffender relationship for purposes of desistance, sex offender management, and societal reintegration. 


\section{REFERENCES}

Abadinsky, H. (2012). Probation and parole: Theory and practice. Upper Saddle River, NJ: Pearson.

Adkins, G., Huff, D., \& Stageberg, P. (2000). The Iowa Sex Offender Registry and recidivism. Des Moines, IA: Iowa Department of Human Rights.

Agan, A.Y. (2007). Sex offender registries: Fear without function? Unpublished manuscript, University of Chicago.

Anderson, A.L., \& Sample, L.L. (2008). Public awareness and action resulting from sex offender community notification laws. Criminal Justice Policy Review, 19(4), 371-396.

Arditti, J.A., Lambert-Shute, J., \& Joest, K. (2003). Saturday morning at the jail: Implications for incarceration for families and children. Family Relations, 52(3), 195-204.

Bales, W.D., \& Mears, D.P. (2008). Inmate social ties and the transition to society: Does visitation reduce recidivism? Journal of Research in Crime and Delinquency, 45(3), 287-321.

Bauldry, S., Korom-Djakovic, D., McClanahan, W.S., McMaken, J., \& Kotloff, L.J. (2009). Mentoring formerly incarcerated adults: Insights from the Ready4Work reentry initiative. New York: Public Private Ventures.

Berg, M.T., \& Huebner, B.M. (2011). Reentry and the ties that bind: An examination of social ties, employment, and recidivism. Justice Quarterly, 28(2), 382-410.

Brannon, Y.N., Levenson, J.S., Fortney, T., \& Baker, J.N. (2007). Attitudes about community notification: A comparison of sexual offenders and the non-offending public. Sexual Abuse: A Journal of Research and Treatment, 19(4), 369-379.

Buckler, K.G., \& Travis, L.F. (2003). Reanalyzing the prevalence and social context of collateral consequence statutes. Journal of Criminal Justice, 31(5), 435-453.

Burchfield, K.B. (2012). Assessing community residents' perceptions of local registered sex offenders: Results from a pilot survey. Deviant Behavior, 33(4), 241-259. 
Burchfield, K.B., \& Mingus, W. (2008). Not in my neighborhood: Assessing registered sex offenders' experiences with local social capital and social control. Criminal Justice and Behavior, 35(3), 356-374.

Burton, V.S., Cullen, F.T., \& Travis, L.F. (1987). The collateral consequences of a felony conviction: A national study of state statutes. Federal Probation, 51(3), 52-60.

Caputo, A.A., \& Brodsky, S.L. (2004). Citizen coping with community notification of released sex offenders. Behavioral Sciences and the Law, 22(2), 239-252.

Center for Sex Offender Management. (2007). Managing the challenges of sex offender reentry. Washington, DC: U.S. Department of Justice.

Charmaz, K. (1983). The grounded theory method: An explication and interpretation. In R. Emerson (Ed.), Contemporary field research (pp. 109-126). Boston: Little and Brown.

Charmaz, K. (2006). Constructing grounded theory: A practical guide through qualitative analysis. London: Sage.

Comartin, E.B., Kernsmith, P.D., \& Kernsmith, R.M. (2009). Sanctions for sex offenders: Fear and public policy. Journal of Offender Rehabilitation, 48(7), 605-619.

Comartin, E.B., Kernsmith, P.D., \& Miles, BW. (2010). Family experiences of young adult sex offender registration. Journal of Child Sexual Abuse, 19(2), 204-225.

Connor, D.P., Copes, H., \& Tewksbury, R. (2011). Incarcerated sex offenders' perceptions of prison sex offender treatment programs. Justice Policy Journal, $8(2)$.

Copes, H., Brown, A., \& Tewksbury, R. (2011). A content analysis of ethnographic research published in top criminology and criminal justice journals from 2000 2009. Journal of Criminal Justice Education, 22(3), 341-359.

Corrigan, P., \& Miller, F.E. (2004). Shame, blame, and contamination: A review of the impact of mental illness stigma on family members. Journal of Mental Health, 13(6), 537-548.

Craun, S.W. (2010). Evaluating awareness of RSOs in the neighborhood. Crime \& Delinquency, 56(3), 414-435.

Craun, S.W., Kernsmith, P.D., \& Butler, N.K. (2011). Anything that can be a danger to the public: Desire to extend registries beyond sex offenses. Criminal Justice Policy Review, 22(3), 375-391. 
Craun, S.W., \& Theriot, M.T. (2009). Misperceptions of sex offender perpetration: Considering the impact of sex offender registration. Journal of Interpersonal Violence, 24(12), 2057-2072.

Davis, F. (1961). Deviance disavowal: The management of strained interaction by the visibly handicapped. Social Problems, 9(2), 120-132.

Denney, A.S., \& Tewksbury, R. (2013). Motivations and the need for fulfillment of faithbased halfway house volunteers. Justice Policy Journal, 10(1).

Dodge, M., \& Pogrebin, M. R. (2001). Collateral costs of imprisonment for women: Complications of reintegration. The Prison Journal, 81(1), 42-54.

Drake, E.K., \& Aos, S. (2009). Does sex offender registration and notification reduce crime? A systematic review of the research literature. Olympia, WA: Washington State Institute for Public Policy.

Duwe, G., \& Clark, V. (2013). Blessed be the social tie that binds: The effects of prison visitation on offender recidivism. Criminal Justice Policy Review, 24(3), 271-296.

Evans, D.N., \& Cubellis, M.A. (2014). Coping with stigma: How registered sex offenders manage their public identities. American Journal of Criminal Justice. DOI: $10.1007 / \mathrm{s} 12103-014-9277-\mathrm{z}$

Farkas, M.A., \& Miller, G. (2007). Reentry and reintegration: Challenges faced by the families of convicted sex offenders. Federal Sentencing Reporter, 20(2), 88-92.

Finn, P. (1997). Sex offender community notification. Washington, DC: National Institute of Justice.

Furby, L., Weinrott, M., \& Blackshaw, L. (1989). Sex offender recidivism: A review. Psychological Bulletin, 105(1), 3-30.

General Accounting Office. (1996). Sex offender treatment: Report to the Chairman, Subcommittee on Crime, Committee on the Judiciary, U.S. House of Representatives. Washington, DC: Author.

Gerardin, P., \& Thibaut, F. (2004). Epidemiology and treatment of juvenile sexual offending. Pediatric Drugs, 6(2), 79-91.

Goffman, E. (1963). Stigma: Notes on the management of a spoiled identity. New York: Touchstone Books.

Goodman, E.A. (1996). Megan's Law: The New Jersey Supreme Court navigates uncharted waters. Seton Hall Law Review, 26(2), 764-802. 
Green, S.E. (2004). The impact of stigma on maternal attitudes toward placement of children with disabilities in residential care facilities. Social Science and Medicine, 59(4), 799-812.

Greenfeld, L.A. (1997). Sex offenses and offenders: An analysis of data on rape and sexual assault. Washington, DC: U.S. Department of Justice.

Guest, G., Bunce, A., \& Johnson, L. (2006). How many interviews are enough? An experiment with data saturation and variability. Field Methods, 18(1), 59-82.

Hall, G.C.N. (1995). Sex offender recidivism revisited: A meta-analysis of recent treatment studies. Journal of Consulting and Clinical Psychology, 63(5), 802-809.

Hannem, S., \& Petrunik, M. (2007). Circles of Support and Accountability: A community justice initiative for the reintegration of high risk sex offenders. Contemporary Justice Review, 10(2), 153-171.

Hanson, R.K., Gordon, A., Harris, A.J., Marques, J.K., Murphy, W., Quinsey, V.L., \& Seto, M.C. (2002). First report of the collaborative outcome data project on the effectiveness of psychological treatment for sex offenders. Sexual Abuse, 14(2), 169-194.

Harding, D. (2003). Jean Valjean's dilemma: The management of ex-convict identity in the search for employment. Deviant Behavior, 24(6), 571-596.

Harris, A., \& Lobanov-Rostovsky, C. (2010). Implementing the Adam Walsh Act's Sex Offender Registration and Notification provisions: A survey of the states. Criminal Justice Policy Review, 21(2), 202-222.

Harrison, P.M., \& Beck, A.J. (2006). Prison and jail inmates at midyear 2005. Washington, DC: U.S. Department of Justice.

Hebl, M.R., \& Kleck, R.E. (2002). Acknowledging one's stigma in the interview setting: Effective strategy or liability? Journal of Applied Social Psychology, 32(2), 223249.

Hebl, M.R., \& Skorinko, J.L. (2005). Acknowledging one's physical disability in the interview: Does "when" make a difference? Journal of Applied Social Psychology, 35(12), 2477-2492.

Hughes, T.A., \& Wilson, D.J. (2003). Reentry trends in the United States. Washington, DC: U.S. Department of Justice.

Jenkins, P. (1998). Moral panic: Changing concepts of the child molester in modern America. New Haven, CT: Yale University Press. 
Jones, R.S. (2003). Excon: Managing a spoiled identity. In J.I. Ross \& S.C. Richards (Eds.), Convict criminology (pp. 191-208). Belmont, CA: Wadsworth.

Justice Policy Institute. (2008). What will it cost states to comply with the Sex Offender Registration and Notification Act? Available from http://www.justicepolicy.org/images/upload/08-08_FAC_SORNACosts_JJ.pdf

Kerley, K.R., Bartkowski, J.P., Matthews, T.L., \& Emond, T.L. (2010). From the sanctuary to the slammer: Exploring the narratives of evangelical prison ministry workers. Sociological Spectrum, 30(5), 504-525.

Kernsmith, P.D., Comartin, E., Craun, S.W., \& Kernsmith, R.M. (2009). The relationship between sex offender registry utilization and awareness. Sexual Abuse, 21(2), 181-193.

Kernsmith, P.D., Craun, S.W., \& Foster, J. (2009). Public attitudes toward sexual offenders and sex offender registration. Journal of Child Sexual Abuse, 18(3), 290-301.

Klein, S.R., Bartholomew, G.S., \& Hibbert, J. (2002). Inmate family functioning. International Journal of Offender Therapy and Comparative Criminology, 46(1), 95-111.

Koro-Ljungberg, M., \& Bussing, R. (2009). The management of courtesy stigma in the lives of families with teenagers with ADHD. Journal of Family Issues, 30(9), 1175-1200.

Kulik, C., Bainbridge, H., \& Cregan, C. (2008). Known by the company we keep: Stigma by association effects in the workplace. Academy of Management Review, 33(1), 231-251.

La Vigne, N.G., Visher, C.A., \& Castro, J.L. (2004). Chicago prisoners' experiences returning home. Washington, DC: Urban Institute.

Langan, P.A., \& Levin, D.J. (2002). Recidivism of prisoners released in 1994. Washington, DC: U.S. Department of Justice.

Larsen, N. (1929). Passing. New York: Alfred A. Knopf.

Laub, J., \& Sampson, R. (2003). Shared beginnings, divergent lives: Delinquent boys to age 70. Boston: Harvard University Press.

Leary, K. (2012). Passing, posing, and "keeping it real.” In L. Aron \& A. Harris (Eds.), Relational psychoanalysis (pp. 31-44). New York: Taylor and Francis.

Leon, C.S. (2011). Sex fiends, perverts, and pedophiles: Understanding sex crime policy in America. New York: New York University Press. 
Letourneau, E.J., Levenson, J.S., Bandyopadhyay, D., Sinha, D., \& Armstrong, K.S. (2010). Effects of South Carolina's sex offender registration and notification policy on deterrence of adult sex crimes. Criminal Justice and Behavior, 37(5), 537-552.

Levenson, J.S., Brannon, Y.N., Fortney, T., \& Baker, J.N. (2007). Public perceptions about sex offenders and community protection policies. Analyses of Social Issues and Public Policy, 7(1), 137-161.

Levenson, J.S., \& Cotter, L.P. (2005a). The effect of Megan's Law on sex offender reintegration. Journal of Contemporary Criminal Justice, 21(1), 49-66.

Levenson, J.S., \& Cotter, L.P. (2005b). The impact of sex offender residence restrictions: 1,000 feet from danger or one step from absurd? International Journal of Offender Therapy and Comparative Criminology, 49(2), 168-178.

Levenson, J.S., D’Amora, D., \& Hern, A. (2007). Megan's Law and its impact on community re-entry for sex offenders. Behavioral Sciences and the Law, 25(4), 587-602.

Levenson, J.S., \& Hern, A. (2007). Sex offender residence restrictions: Unintended consequences and community re-entry. Justice Research and Policy, 9(2), 59-73.

Levenson, J.S., \& Tewksbury, R. (2009). Collateral damage: Family members of registered sex offenders. American Journal of Criminal Justice, 34(1/2), 54-68.

Logan, W.A. (2009). Knowledge as power: Criminal registration and community notification laws in America. Stanford: Stanford University Press.

Losel, F., \& Schmucker, M. (2005). The effectiveness of treatment for sexual offenders: A comprehensive meta-analysis. Journal of Experimental Criminology, 1(1), 117146.

MacRae, H. (1999). Managing courtesy stigma: The case of Alzheimer's disease. Sociology of Health and Illness, 21(1), 54-70.

Maddan, S. (2008). The labeling of sex offenders. Lanham, MD: University Press of America.

Mancini, C., Shields, R.T., Mears, D.P., \& Beaver, K.M. (2010). Sex offender residence restriction laws: Parental perceptions and public policy. Journal of Criminal Justice, 38(5), 1022-1030.

Meloy, M. (2006). Sex offenses and the men who commit them. Boston, MA: Northeastern University Press. 
Mercado, C.C., Alvarez, S., \& Levenson, J.S. (2008). The impact of specialized sex offender legislation on community re-entry. Sexual Abuse, 20(2), 188-205.

Mustaine, E.E., \& Tewksbury, R. (2013). What can be learned from an online sex offender registry site? An 8 year follow-up. Journal of Community Corrections, 23(1), 5-10.

Mustaine, E.E., Tewksbury, R., Connor, D.P., \& Payne, B.K. (2015). Criminal justice officials' views of sex offenders, sex offender registration, community notification, and residency restrictions. Justice System Journal, 36(1), 63-85.

Naser, R., \& Visher, C.A. (2006). Family members' experiences with incarceration and reentry. Western Criminology Review, 7(2), 20-31.

National Center for Missing and Exploited Children. (2014). Map of registered sex offenders in the United States. Washington, DC: Author.

National Conference of State Legislatures. (2014). Adam Walsh Child Protection and Safety Act. Retrieved from http://www.ncsl.org/research/civil-and-criminaljustice/adam-walsh-child-protection-and-safety-act.aspx

Nelson, M., Dees, P., \& Allen, C. (1999). The first month out. New York: Vera Institute of Justice.

Olivares, K.M., Burton, V.S., \& Cullen, F.T. (1996). The collateral consequences of a felony conviction: A national study of state legal codes 10 years later. Federal Probation, 60(3), 10-17.

Patel, S.H., Lambie, G.W., \& Glover, M.M. (2008). Motivational counseling: Implications for counseling juvenile sex offenders. Journal of Addictions and Offender Counseling, 28(2), 86-100.

Payne, B.K., Tewksbury, R., \& Mustaine, E.E. (2013). Identifying the source of community corrections professionals' attitudes about sex offender residence restriction policies: The impact of demographics and perceptions. Crime \& Delinquency. DOI: 10.1177/0011128712470993

Pescosolido, B.A. (2013). The public stigma of mental illness: What do we think; what do we know; what can we prove? Journal of Health and Social Behavior, 54(1), $1-21$.

Petersilia, J. (2003). When prisoners come home: Parole and prisoner reentry. New York: Oxford University Press. 
Petrosino, A. J., \& Petrosino, C. (1999). The public safety potential of Megan's Law in Massachusetts: An assessment from a sample of criminal sexual psychopaths. Crime \& Delinquency, 45(1), 140-158.

Petrunik, M. (2003). The hare and the tortoise: Dangerousness and sex offender policy in the United States and Canada. Canadian Journal of Criminology and Criminal Justice, 45(1), 43-72.

Pogrebin, M.R., Dodge, M., \& Katsampes, P. (2001). The collateral costs of short-term jail incarceration: The long-term social and economic disruptions. Corrections Management Quarterly, 5(4), 64-69.

Powell, M., Day, A., Benson, M., Vess, J., \& Graffam, J. (2014). Police officers' perceptions of interviewing offenders on sex offender registries. International Journal of Police Science and Management, 16(4), 255-266.

Prentky, R., \& Schwartz, B. (2006). Treatment of adult sex offenders. Harrisburg, PA: VAWnet, National Resource Center on Domestic Violence/Pennsylvania Coalition against Domestic Violence.

Prescott, J. J., \& Rockoff, J. E. (2011). Do sex offender registration and notification laws affect criminal behavior? Journal of Law and Economics, 54(1), 161-206.

Quinn, J., Forsyth, C., \& Mullen-Quinn, C. (2004). Societal reaction to sex offenders: A review of the origins and results of the myths surrounding their crimes and treatment amenability. Deviant Behavior, 25(3), 215-233.

Robbers, M.L.P. (2009). Lifers on the outside: Sex offenders and disintegrative shaming. International Journal of Offender Therapy and Comparative Criminology, 53(1), $5-28$.

Salmon, T.M. (2010). Sex offender registry: Report of the Vermont State Auditor. Montpelier, VT: Office of the State Auditor.

Sample, L.L., \& Bray, T.M. (2003). Are sex offenders dangerous? Journal of Criminology \& Public Policy, 3(1), 59-82.

Sample, L.L., \& Bray, T.M. (2006). Are sex offenders different? An examination of rearrest patterns. Criminal Justice Policy Review, 17(1), 83-102.

Sandler, J.C., Freeman, N.J., \& Socia, K.M. (2008). Does a watched pot boil? A timeseries analysis of New York State's sex offender registration and notification law. Psychology, Public Policy, and Law, 14(4), 284-302. 
Schiavone, S.K., \& Jeglic, E.L. (2009). Public perceptions of sex offender social policies and the impact on sex offenders. International Journal of Offender Therapy and Comparative Criminology, 35(6), 679-695.

Schram, D.D., \& Milloy, C.D. (1995). Community notification: A study of offender characteristics and recidivism. Olympia, WA: Washington Institute for Public Policy.

Siegel, K., Lune, H., \& Meyer, I.H. (1998). Stigma management among gay/bisexual men with HIV/AIDS. Qualitative Sociology, 21(1), 3-24.

Sigelman, C.K., Howell, J.L., Cornell, D.P., Cutright, J.D., \& Dewey, J.C. (1991). Courtesy stigma: The social implications of associating with a gay person. Journal of Social Psychology, 131(1), 45-56.

Simon, J. (1998). Managing the monstrous: Sex offenders and the new penology. Psychology, Public Policy, and the Law, 4(1/2), 452-467.

Singletary, S.L., \& Hebl, M.R. (2009). Compensatory strategies for reducing interpersonal discrimination: The effectiveness of acknowledgments, increased positivity, and individuating information. Journal of Applied Psychology, 94(3), $797-805$

Stalans, L.J. (2004). Adult sex offenders on community supervision: A review of recent assessment strategies and treatment. Criminal Justice and Behavior, 31(5), 564608.

Sullivan, E., Mino, M., Nelson, K., \& Pope, J. (2002). Families as a resource in recovery from drug abuse: An evaluation of La Bodega de la Familia. Washington, DC: Vera Institute of Justice.

Terry, K.J. (2013). Sexual offenses and offenders. Belmont, CA: Wadsworth.

Tewksbury, R. (2002). Validity and utility of the Kentucky Sex Offender Registry. Federal Probation, 66(1), 21-26.

Tewksbury, R. (2004). Experiences and attitudes of registered female sex offenders. Federal Probation, 68(3), 30-33.

Tewksbury, R. (2005). Collateral consequences of sex offender registration. Journal of Contemporary Criminal Justice, 21(1), 67-81.

Tewksbury, R. (2012). Stigmatization of sex offenders. Deviant Behavior, 33(8), 606623.

Tewksbury, R. (2013). Sex offenders and campus-based sex offender registration: 
Stigma, vulnerability, isolation, and the classroom as refuge. Journal of Qualitative Criminology and Criminal Justice, 1(2), 221-242.

Tewksbury, R., \& Connor, D.P. (2012a). Inmate reentry. In D. McDonald \& A. Miller (Eds.), Race, gender, and criminal justice: Equality and justice for all? (pp. 141157). San Diego, CA: Cognella Academic Publishing.

Tewksbury, R., \& Connor, D.P. (2012b). Incarcerated sex offenders' perceptions of family relationships: Previous experiences and future expectations. Western Criminology Review, 13(2), 25-35.

Tewksbury, R., \& Connor, D.P. (2014). Sex offenders and criminal policy. In G. Bruinsma \& D. Weisburd (Eds.), Encyclopedia of Criminology and Criminal Justice (pp. 4782-4791). New York: Springer.

Tewksbury, R., \& Higgins, G.E. (2005). What can be learned from an online sex offender registry site? Journal of Community Corrections, 14(3), 9-11, 15-16.

Tewksbury, R., \& Humkey, T. (2010). Prohibiting registered sex offenders from being at school: Assessing the collateral consequences of a public policy. Justice Policy Journal, $7(2)$.

Tewksbury, R., \& Jennings, W.G. (2010). Assessing the impact of sex offender registration and community notification on sex offending trajectories. Criminal Justice and Behavior, 37(5), 570-582.

Tewksbury, R., Jennings, W.G., \& Zgoba, K.M. (2012). A longitudinal examination of sex offender recidivism prior to and following the implementation of SORN. Behavioral Sciences and the Law, 30(3), 308-328.

Tewksbury, R., \& Lees, M.B. (2006a). Perceptions of sex offender registration: Collateral consequences and community experiences. Sociological Spectrum, 26(3), 309334.

Tewksbury, R., \& Lees, M.B. (2006b). Sex offenders on campus: University-based sex offender registries and collateral consequences of registration. Federal Probation, 70(3), 50-56.

Tewksbury, R., \& Lees, M.B. (2007). Perceptions of punishment: How registered sex offenders view registries. Crime \& Delinquency, 53(3), 380-407.

Tewksbury, R., \& Levenson, J.S. (2009). Stress experiences of family members of registered sex offenders. Behavioral Sciences and the Law, 27(4), 611-626.

Tewksbury, R., \& McGaughey, D. (1997). Stigmatization of persons with HIV disease: 
Perceptions, management and consequences of AIDS. Sociological Spectrum, 17(1), 49-70.

Tewksbury, R., \& Mustaine, E.E. (2006). Where to find sex offenders: An examination of residential locations and neighborhood conditions. Criminal Justice Studies, 19(1), 61-75.

Tewksbury, R., \& Mustaine, E.E. (2008). Where registered sex offenders live: Community characteristics and proximity to possible victims. Victims and Offenders, 3(1), 86-98.

Tewksbury, R., \& Mustaine, E.E. (2009). Stress and collateral consequences for registered sex offenders. Journal of Public Management and Social Policy, 15(2), 215-239.

Tewksbury, R., \& Mustaine, E.E. (2012). Parole board members' views of sex offender registration and community notification. American Journal of Criminal Justice, $37(3), 413-431$.

Travis, J., Solomon, A.L., \& Waul, M. (2001). From prison to home: The dimensions and consequences of prisoner reentry. Washington, DC: Urban Institute.

Uggen, C., Manza, J., \& Behrens, A. (2004). Less than the average citizen: Stigma, role transition and civic reintegration of convicted felons. In S. Maruna \& R. Immarigeon (Eds.), After crime and punishment: Pathways to offender reintegration (pp. 258-290). Devon, UK: Willan Publishing.

Vandiver, D.M., \& Walker, J.T. (2002). Female sex offenders: An overview and analysis of 40 cases. Criminal Justice Review, 27(2), 284-300.

Vecina, M.L., Chacon, F., Sueiro, M., \& Barron, A. (2012). Volunteer engagement: Does engagement predict the degree of satisfaction among new volunteers and the commitment of those who have been active longer? Applied Psychology, 61(1), 130-148.

Virginia Department of Planning and Budget. (2008). Fiscal impact statement. Richmond, VA: Author.

Visher, C.A., \& Courtney, S.M.E. (2006). Cleveland prisoners' experiences returning home. Washington, DC: Urban Institute.

Visher, C.A., Kachnowski, V., La Vigne, N.G., \& Travis, J. (2004). Baltimore prisoners' experiences returning home. Washington, DC: Urban Institute.

Visher, C.A., La Vigne, N.G., \& Travis, J. (2004). Returning home: Understanding the 
challenges of prisoner reentry: Maryland pilot study: Findings from Baltimore. Washington, DC: Urban Institute.

Visher, C.A., Yahner, J., \& La Vigne, N. (2010). Life after prison: Tracking the experiences of male prisoners returning to Chicago, Cleveland, and Houston. Washington, DC: Urban Institute.

Werner, P., Goldstein, D., \& Buchbinder, E. (2010). Subjective experience of family stigma as reported by children of Alzheimer's disease patients. Qualitative Health Research, 20(2), 159-169.

Wheelock, D. (2005). Collateral consequences and racial inequality: Felon status restrictions as a system of disadvantage. Journal of Contemporary Criminal Justice, 2l(1), 82-90.

Williams, F.M. (2009). The problem of sexual assault. In R.G. Wright (Ed.), Sex offender laws: Failed policies, new directions (pp. 17-63). New York: Springer.

Wilson, J.A., \& Davis, R.C. (2006). Good intentions meet hard realities: An evaluation of the Project Greenlight reentry program. Criminology \& Public Policy, 5(2), 303338.

Wilson, R.J. (2007). Habilitation or harm: Project Greenlight and the potential consequences of correctional programming. National Institute of Justice Journal, 257.

Wilson, R.J., Picheca, J., \& Prinzo, M. (2005). Circles of Support and Accountability: An evaluation of the pilot project in South-Central Ontario. Ottawa: Correctional Services Canada.

Woods, J.D. (1994). The corporate closet. New York: Free Press.

Zgoba, K.M., \& Simon, L.M.J. (2005). Recidivism rates of sexual offenders up to 7 years later: Does treatment matter? Criminal Justice Review, 30(2), 155-173.

Zgoba, K.M, Witt, P., Dalessandro, M., \& Veysey, B. (2008). Megan's Law: Assessing the practical and monetary efficacy. Washington, DC: National Institute of Justice.

Zevitz, R.G. (2006). Sex offender community notification: Its role in recidivism and offender reintegration. Criminal Justice Studies, 19(2), 193-208.

Zevitz, R.G., \& Farkas, M.A. (2000a). Sex offender community notification: Managing high risk criminals or exacting further vengeance? Behavioral Sciences and the Law, 18(2/3), 375-391. 
Zevitz, R.G., \& Farkas, M.A. (2000b). The impact of sex-offender community notification on probation/parole in Wisconsin. International Journal of Offender Therapy and Comparative Criminology, 44(1), 8-21.

Zilney, L.J., \& Zilney, L.A. (2009). Perverts and predators: The making of sexual offending laws. Lanham, MA: Rowman \& Littlefield. 


\section{CURRICULUM VITAE \\ DAVId Patrick ConNor}

\section{Current Position}

\section{Doctoral Candidate}

Department of Justice Administration

College of Arts and Sciences

University of Louisville

Brigman Hall 106

Louisville, KY 40292

859-486-3542

david.connor@louisville.edu

\section{RESEARCH INTERESTS}

- Sex offenders and sex crimes

- Institutional corrections

- Community corrections

- Inmate reentry

- Social deviance

\section{EDUCATION}

Ph.D. University of Louisville, Justice Administration

MAY 2015

Dissertation: Support Partners of Registered Sex Offenders: Exploring Their

Experiences, Identities, and Perceptions

Dr. Richard Tewksbury, Chair

M.S. University OF LOUISVILLE, Justice Administration

MAY 2012

Thesis: Prison Wardens' Perceptions of Sex Offenders, Sex Offender Registration, Community Notification, and Residency Restrictions

Dr. Richard Tewksbury, Chair

B.A. Northern Kentucky University, Radio/Television

MAY 2009

Summa Cum Laude

Minor in Criminal Justice

\section{Publications}




\section{Peer-Reviewed Articles}

Connor, D.P., \& Tewksbury, R. (forthcoming). Prison inmates and their visitors: An examination of inmate characteristics and visitor types. The Prison Journal.

Mustaine, E.E., Tewksbury, R., Connor, D.P., \& Payne, B.K. (2015). Criminal justice officials' views of sex offenders, sex offender registration, community notification, and residency restrictions. The Justice System Journal, 36(1), 63-85.

Tewksbury, R., \& Connor, D.P. (2014). Who is having sex inside prison? Deviant Behavior, 35(12), 993-1005.

Tewksbury, R., Connor, D.P., \& Denney, A.S. (2014). Disciplinary infractions behind bars: An exploration of importation and deprivation theories. Criminal Justice Review, 39(2), 201-218.

Tewksbury, R., Higgins, G.E., \& Connor, D.P. (2013). Number of sexual partners and social disorganization: A developmental trajectory approach. Deviant Behavior, $34(12), 1020-1034$.

Tewksbury, R., Connor, D.P., \& Worley, R.M. (2013). Why the American Journal of Criminal Justice is a great place to publish: A research note examining frequent authors' experiences. American Journal of Criminal Justice, 38(3), 341-347.

Tewksbury, R., \& Connor, D.P. (2012). Inmates who receive visits in prison: Exploring factors that predict. Federal Probation, 76(3), 43-46.

Tewksbury, R., Connor, D.P., Cheeseman, K., \& Rivera, B.L. (2012). Female sex offenders' anticipations for re-entry: Do they really know what they're in for? Journal of Crime and Justice, 35(3), 451-463.

Tewksbury, R., \& Connor, D.P. (2012). Incarcerated sex offenders' perceptions of family relationships: Previous experiences and future expectations. Western Criminology Review, 13(2), 25-35.

Connor, D.P., \& Tewksbury, R. (2012). Ex-offenders and educational equal access: Doctoral programs in criminology and criminal justice. Critical Criminology, 20(3), 327-340.

Connor, D.P., \& Tewksbury, R. (2012). Social control on public buses. Journal of Theoretical and Philosophical Criminology, 4(1), 1-13.

Connor, D.P., Copes, H., \& Tewksbury, R. (2011). Incarcerated sex offenders' perceptions of prison sex offender treatment programs. Justice Policy Journal, $8(2)$. 


\section{Book Chapters}

Connor, D.P. (2015). Community corrections. In R. Tewksbury, Introduction to corrections (pp. 185-211). New York: Wolters Kluwer.

Connor, D.P. (2015). Jails and local corrections. In R. Tewksbury, Introduction to corrections (pp. 161-184). New York: Wolters Kluwer.

Connor, D.P. (2015). Corrections for women. In R. Tewksbury, Introduction to corrections (pp. 147-160). New York: Wolters Kluwer.

Tewksbury, R., \& Connor, D.P. (2014). Sexual victimization. In C.D. Marcum \& T.L. Castle (Eds.), Sex in prison: Myths and realities (pp. 25-51). Boulder, CO: Lynne Rienner.

Tewksbury, R., \& Connor, D.P. (2014). From troubling actions to troubled lives: Sex offender registration and notification. In J.F. Gubrium \& M. Jarvinen (Eds.), Turning troubles into problems: Clientization in human services (pp. 211-227). London: Routledge.

Tewksbury, R., Holmes, R.M., \& Connor, D.P. (2013). Typologies of teenage suicide: Analyzing suicide notes through Durkheimian categories. In T. Calhoun, A. Thio, \& A. Conyers (Eds.), Deviance today (pp. 155-166). Boston, MA: Pearson Education.

Tewksbury, R., \& Connor, D.P. (2012). Inmate reentry. In D. McDonald \& A. Miller (Eds.), Race, gender, and criminal justice: Equality and justice for all? (pp. 141157). San Diego, CA: Cognella Academic Publishing.

\section{Book Reviews}

Connor, D.P. (2012). Book review: Sex fiends, perverts, and pedophiles: Understanding sex crime policy in America. Criminal Law and Criminal Justice Books. Available online at http://clcjbooks.rutgers.edu/books/sex_fiends_perverts_pedophiles.html

Connor, D.P. (2011). Book review: Explaining U.S. imprisonment. Criminal Justice Review, 36(4), 519-521.

\section{Technical Reports}

Tewksbury, R., \& Connor, D.P. (2011). Needs of sex offenders approaching release: Report prepared for the Kentucky Department of Corrections. 


\section{Encyclopedia Articles}

Connor, D.P. (2014). Norms and societal expectations. In H. Copes \& C.J. Forsyth (Eds.), Encyclopedia of Social Deviance (Vol. 2, pp. 470-471). Thousand Oaks, CA: Sage.

Connor, D.P. (2014). Stigma and stigma management. In H. Copes \& C.J. Forsyth (Eds.), Encyclopedia of Social Deviance (Vol. 2, pp. 691-694). Thousand Oaks, CA: Sage.

Tewksbury, R., \& Connor, D.P. (2014). Sex offenders and criminal policy. In G. Bruinsma \& D. Weisburd (Eds.), Encyclopedia of Criminology and Criminal Justice (pp. 4782-4791). New York: Springer.

\section{Other Publications}

Connor, D.P., \& Tewksbury, R. (2013). Examining prison wardens' perceptions of inmates incarcerated for sex offenses. Corrections Today, 75(3), 60-61, 68.

Tewksbury, R., \& Connor, D.P. (2012). Predicting the outcome of parole hearings. Corrections Today, 74(3), 54-56.

\section{Presentations}

Connor, D.P. (March 2015). How to get out of prison: Views from parole board members. Paper presented at the annual meeting of the Academy of Criminal Justice Sciences, Orlando, FL.

Connor, D.P., \& Tewksbury, R. (November 2014). Who is having sex inside prison? Paper presented at the annual meeting of the American Society of Criminology, San Francisco, CA.

Connor, D.P., \& Tewksbury, R. (September 2014). Inmates and prison involvement with drugs: Examining drug-related misconduct during incarceration. Paper presented at the annual meeting of the Southern Criminal Justice Association, Clearwater, FL.

Connor, D.P., \& Tewksbury, R. (February 2014). Prison inmates and their visitors: An examination of inmate characteristics and visitor types. Paper presented at the annual meeting of the Academy of Criminal Justice Sciences, Philadelphia, PA.

Connor, D.P., Denney, A.S., \& Tewksbury, R. (November 2013). Disciplinary infractions behind bars: Exploring inmate demographics and prison experience. Paper presented at the annual meeting of the American Society of Criminology, Atlanta, GA. 
Tewksbury, R., \& Connor, D.P. (September 2013). Who is having sex inside prison? Poster presented at the annual meeting of the Southern Criminal Justice Association, Virginia Beach, VA.

Denney, A.S., Connor, D.P., Vito, A.G., \& Cruze, J. (September 2013). Tips for first-time teachers in criminology/criminal justice. Roundtable convened at the annual meeting of the Southern Criminal Justice Association, Virginia Beach, VA.

Cheeseman, K., Rivera, B.L., Tewksbury, R., \& Connor, D.P. (March 2013). Exploring the connection between female sex offending and a history of abuse. Poster presented at the annual meeting of the Academy of Criminal Justice Sciences, Dallas, TX.

Connor, D.P., \& Tewksbury, R. (March 2013). Inmates who receive visits in prison: Exploring factors that predict. Paper presented at the annual meeting of the Academy of Criminal Justice Sciences, Dallas, TX.

Denney, A.S., Connor, D.P., Cruze, J., Kirchner, E., \& Magers, M. (March 2013). Successful strategies for transitioning from a criminology/criminal justice master's program to a Ph.D. program. Roundtable convened at the annual meeting of the Academy of Criminal Justice Sciences, Dallas, TX.

Connor, D.P., \& Tewksbury, R. (November 2012). Inside the parole hearing: Structural and interactional influences on parole decisions. Paper presented at the annual meeting of the American Society of Criminology, Chicago, IL.

Connor, D.P. (September 2012). Prison wardens' perceptions of sex offender registration, community notification, and residency restrictions. Paper presented at the annual meeting of the Southern Criminal Justice Association, Atlantic Beach, FL.

Connor, D.P., \& Tewksbury, R. (February 2012). Incarcerated sex offenders' perceptions of family relationships: Previous experiences and future expectations. Paper presented at the annual meeting of the American Association of Behavioral and Social Sciences, Las Vegas, NV.

Connor, D.P., \& Tewksbury, R. (November 2011). Ex-offenders and educational equal access: Doctoral programs in criminology and criminal justice. Paper presented at the annual meeting of the American Society of Criminology, Washington, DC.

Connor, D.P., Copes, H., \& Tewksbury, R. (September 2011). Incarcerated sex offenders' perceptions of prison sex offender treatment programs. Paper presented at the annual meeting of the Southern Criminal Justice Association, Nashville, TN. 
Faculty Favorite Outstanding Professor Award

Delphi Center for Teaching and Learning

UNIVERSITY OF LOUISVILLE, Louisville, KY

Graduate Teaching Assistantship Appointment

Department of Justice Administration

UNIVERSITY OF LOUISVILLE, Louisville, KY

Tuition Match Award

$2012-2013$

School of Interdisciplinary and Graduate Studies

UNIVERSITY OF LOUISVILLE, Louisville, KY

Graduate Dean's Citation

SPRING 2012

School of Interdisciplinary and Graduate Studies

UNIVERSITY OF LOUISVILLE, Louisville, KY

Kenneth J. Marshall Award Nominee

SPRING 2012

Department of Justice Administration

UNIVERSITY OF LOUISVILLE, Louisville, KY

Graduate Research Assistantship Appointment

Department of Justice Administration

UNIVERSITY OF LOUISVILLE, Louisville, KY

Top Scholar Award

SPRING 2009

Department of Communication

NORTHERN KENTUCKY UnIVERSITY, Highland Heights, KY

\section{TEACHING EXPERIENCE}

Instructor

FALL 2014

Department of Justice Administration

UNIVERSITY OF LOUISVILLE, Louisville, KY

- JA 326 - Quantitative Analysis (on campus)

○ Enrollment: 24

○ Overall Teaching Evaluation Score: 4.63 out of 5.00

- JA 360 - Juvenile Justice (on campus)

○ Enrollment: 63

$\circ$ Overall Teaching Evaluation Score: 4.54 out of 5.00

Instructor

SUMMER 2014

Department of Justice Administration

UNIVERSITY OF LOUISVILLE, Louisville, KY 
- JA 403 - Prisons and Jails (online)

○ Enrollment: 40

$\circ$ Overall Teaching Evaluation Score: 3.72 out of 5.00

\section{Instructor}

SPRING 2014

Department of Justice Administration

UNIVERSITY OF LOUISVILLE, Louisville, KY

- JA 360 - Juvenile Justice (on campus)

○ Enrollment: 44

$\circ$ Overall Teaching Evaluation Score: 4.76 out of 5.00

\section{Instructor}

FALL 2013

Department of Justice Administration

UNIVERSITY OF LOUISVILLE, Louisville, KY

- JA 326 - Quantitative Analysis (on campus)

○ Enrollment: 24

○ Overall Teaching Evaluation Score: 4.54 out of 5.00

- JA 360 - Juvenile Justice (on campus)

○ Enrollment: 26

$\circ$ Overall Teaching Evaluation Score: 4.72 out of 5.00

Instructor

SPRING 2013

Department of Justice Administration

UNIVERSITY OF LOUISVILLE, Louisville, KY

- JA 305 - Criminal Behavior (on campus)

○ Enrollment: 66

○ Overall Teaching Evaluation Score: 4.36 out of 5.00

Graduate Teaching Assistant

SUMMER 2011

Department of Justice Administration

UNIVERSITY OF LOUISVILLE, Louisville, KY

- JA 326 - Quantitative Analysis (on campus)

Teaching Assistant

SPRING 2009

Office of First-Year Programs

NORTHERN KENTUCKY UNIVERSITY, Highland Heights, KY

- UNV 101 - Orientation to College and Beyond (on campus)

\section{Professional Service}

Ad Hoc Manuscript Reviewer

2012 - PRESENT

- American Journal of Criminal Justice

- Ethnography

- Journal of Criminal Justice Education

Graduate Student Ambassador

2012 - PRESENT 
School of Interdisciplinary and Graduate Studies

UNIVERSITY OF LOUISVILLE, Louisville, KY

Professional AfFiliations

Academy of Criminal Justice Sciences

2013 - PRESENT

American Society of Criminology

2009 - PRESENT

Southern Criminal Justice Association

2011 - PRESENT

REFERENCES

\section{Richard Tewksbury}

Professor

Department of Justice Administration

College of Arts and Sciences

University of Louisville

Louisville, KY 40292

502-852-0379

richard.tewksbury@louisville.edu

\section{Elizabeth Ehrhardt Mustaine}

Professor, Chair

Department of Sociology

College of Sciences

University of Central Florida

Orlando, FL 32816

407-823-3744

elizabeth.mustaine@ucf.edu

\section{Geetha Suresh}

Associate Professor

Criminal Justice Program

School of Humanities and Social Sciences

Stevenson University

Stevenson, MD 21153

443-334-2191

gsuresh@stevenson.edu

\section{Deborah G. Keeling}

Associate Dean

Faculty Affairs

Professor

Department of Justice Administration

College of Arts and Sciences 
University of Louisville

Louisville, KY 40292

502-852-2237

502-852-0370

deborah.wilson@louisville.edu 